\title{
Review of the Estimation Methods of Energy Consumption for Battery Electric Buses
}

\author{
Ali Saadon Al-Ogaili ${ }^{1}$, Ali Q. Al-Shetwi ${ }^{2,3}$, Hussein M. K. Al-Masri $\left.{ }^{4}{ }^{(}\right)$, Thanikanti Sudhakar Babu ${ }^{5} \mathbb{D}^{\text {, }}$ \\ Yap Hoon ${ }^{6}$, Khaled Alzaareer ${ }^{7}$ and N. V. Phanendra Babu ${ }^{5, *}$ \\ 1 After Sale Department, HelioxCompany, De Waal 24, 5684 PH Best, The Netherlands; \\ ali.al-olgaili@heliox-energy.com \\ 2 Electrical Engineering Department, Fahad Bin Sultan University, Tabuk 47721, Saudi Arabia; \\ aalshetwi@fbsu.edu.sa \\ 3 Department of Renewable Energy Engineering, Fahad Bin Sultan University, Tabuk 47721, Saudi Arabia \\ 4 Department of Electrical Power Engineering, Yarmouk University, Irbid 21163, Jordan; h.almasri@yu.edu.jo \\ 5 Department of Electrical and Electronics Engineering, Chaitanya Bharathi Institute of Technology, \\ Hyderabad 500075, India; sudhakarbabu@ieee.org \\ 6 School of Engineering, Faculty of Innovation and Technology, Taylor's University, \\ Subang Jaya 47500, Selangor, Malaysia; yap.hoon@taylors.edu.my \\ 7 Electrical Engineering Department, Faculty of Engineering, Philadelphia University, Amman 19392, Jordan; \\ khaled.alzaareer.1@ens.etsmtl.ca \\ * Correspondence: phanendrababu_eee@cbit.ac.in
}

check for updates

Citation: Al-Ogaili, A.S.; Al-Shetwi, A.Q.; Al-Masri, H.M.K.; Babu, T.S.; Hoon, Y.; Alzaareer, K.; Babu, N.V.P. Review of the Estimation Methods of Energy Consumption for Battery Electric Buses. Energies 2021, 14, 7578 http://doi.org/10.3390/en14227578

Academic Editor: Islam Safak Bayram

Received: 25 September 2021

Accepted: 6 November 2021

Published: 12 November 2021

Publisher's Note: MDPI stays neutral with regard to jurisdictional claims in published maps and institutional affiliations.

Copyright: (c) 2021 by the authors. Licensee MDPI, Basel, Switzerland. This article is an open access article distributed under the terms and conditions of the Creative Commons Attribution (CC BY) license (https:/ / creativecommons.org/licenses/by/ $4.0 /)$.

\begin{abstract}
In the transportation sector, electric battery bus (EBB) deployment is considered to be a potential solution to reduce global warming because no greenhouse gas (GHG) emissions are directly produced by EBBs. In addition to the required charging infrastructure, estimating the energy consumption of buses has become a crucial precondition for the deployment and planning of electric bus fleets. Policy and decision-makers may not have the specific tools needed to estimate the energy consumption of a particular bus network. Therefore, many state-of-the-art studies have proposed models to determine the energy demand of electric buses. However, these studies have not critically reviewed, classified and discussed the challenges of the approaches that are applied to estimate EBBs' energy demands. Thus, this manuscript provides a detailed review of the forecasting models used to estimate the energy consumption of EBBs. Furthermore, this work fills the gap by classifying the models for estimating EBBs' energy consumption into small-town depot and big-city depot networks. In brief, this review explains and discusses the models and formulations of networks associated with well-to-wheel (WTW) assessment, which can determine the total energy demand of a bus network. This work also reviews a survey of the most recent optimization methods that could be applied to achieve the optimal pattern parameters of EBB fleet systems, such as the bus battery capacity, charger rated power and the total number of installed chargers in the charging station. This paper highlights the issues and challenges, such as the impact of external factors, replicating real-world data, big data analytics, validity index, and bus routes' topography, with recommendations on each issue. Also, the paper proposes a generic framework based on optimization algorithms, namely, artificial neural network (ANN) and particle swarm optimization (PSO), which will be significant for future development in implementing new energy consumption estimation approaches. Finally, the main findings of this manuscript further our understanding of the determinants that contribute to managing the energy demand of EBBs networks.
\end{abstract}

Keywords: battery electric buses; well-to-wheel (WTW) model; energy consumption forecast; transportation networks; data analysis

\section{Introduction}

In the last few decades, environmental pollution, global warming, depletion of fossil fuels, increasing fuel costs, and growing consumer expectations have led automobile 
manufacturing to shift away from internal combustion engine (ICE) vehicles [1-4]. Public transportation is a crucial factor in contributing to the functionality of urban sustainability networks. In this regard, the deployment of electric bus fleets is becoming a significant issue for many urban communities throughout the world [5]. In China, for example, there were 1,251,000 electric city buses registered in 2016. As of today, in Europe, around 4000 electric buses are in use [6]. Recently, much attention has been given to limiting environmental pollution by reducing the greenhouse gas (GHG) emissions of the transport fleet to improve the services and quality [7]. As a result, electricbuses (EBs) are considered the most promising replacements for GHG emissions in populated regions as global energy shifts towards decarbonization. Compared to typical diesel-powered buses, EBs emit no tailpipe emissions, which is especially useful for buses operating in metropolitan areas, such as city buses [8].

According to the bus type, the EB market is segmented into the parallel hybrid electric bus (HEB), series HEB, and battery electric bus (BEB). As shown in Figure 1, which indicates the market share of BEB, series HEB, and parallel HEB from 2013 to 2025, BEB is the dominant category in terms of volume [9-11]. Additionally, the BEB market is predicted to expand significantly during the forecast period owing to lowering battery prices and the low carbon emissions it delivers [11]. Additionally, the growth of new technologies and opportunities for interdependency between mobility and electric power generation are arising as a result of the move to renewable power sources. This fresh surge in interest in renewable energy has led to the adoption of more BEB technologies. BEBs with the prospective diffusion of bus-to-grid integration (BGI) technologies can offer several benefits. Compared to HEBs, BEBs with larger energy storage systems, e.g., lithium iron phosphate ( $\mathrm{LiFePO} 4)$ batteries, typically have more potential to support load balancing, buck-up electricity power, regulate voltage and frequency, reduce peak-loads, decrease the uncertainty in grid load forecasts, and increase the adoption of renewable energy $[1,12]$. Thus, BEBs in public transit offer significant potential for rapid electrification of the fleet. In such a context, BEBs provide centralized depot locations, fixed routes, and shared infrastructure [13-15]. In this respect, the BEB could be tested, operationalized, and optimized to estimate the required energy demand. Hence, the BEB is operationalized in two forms: overnight and opportunity [16]. Range, battery pack size, and charging time are considered as the main differences between the two types. The battery pack on an electric opportunity bus is smaller than that of an overnight electric bus, which has a limited range (20-30 miles) and can be fully charged in 5-10 min by utilizing a pantograph charging approach with a power range of 350-450 kW. On the other hand, the overnight electric bus has a larger battery pack with a range of up to 200 miles and a much longer charging period (2-4 h) when charging at a depot with a power rating of 40-50 kW [8].

To acquire the data that would be utilized to estimate the energy consumption within the fleet of the bus, standard driving cycles are taken from the most common standardized driving bus cycles. Multiple driving cycle standards of different cities such as New York (United States), Paris (France), and Braunschweig (Germany) have been used widely in the literature to assess the driving cycles of diverse districts. Thus, researchers frequently select a driving cycle similar to the circumstances in their study area. For example, in [17], the authors selected multiple driving cycle standards that had the same number of bus stops as their research location. Several studies have collected extensive driving cycle data from municipal transit bus fleets that are indicative of real-world routes run by traditional diesel-powered buses. In a case study, the researchers examined the performance of batteryelectric buses in Knoxville city in the US based on real day-to-day routes of the city transit bus fleet [18]. 


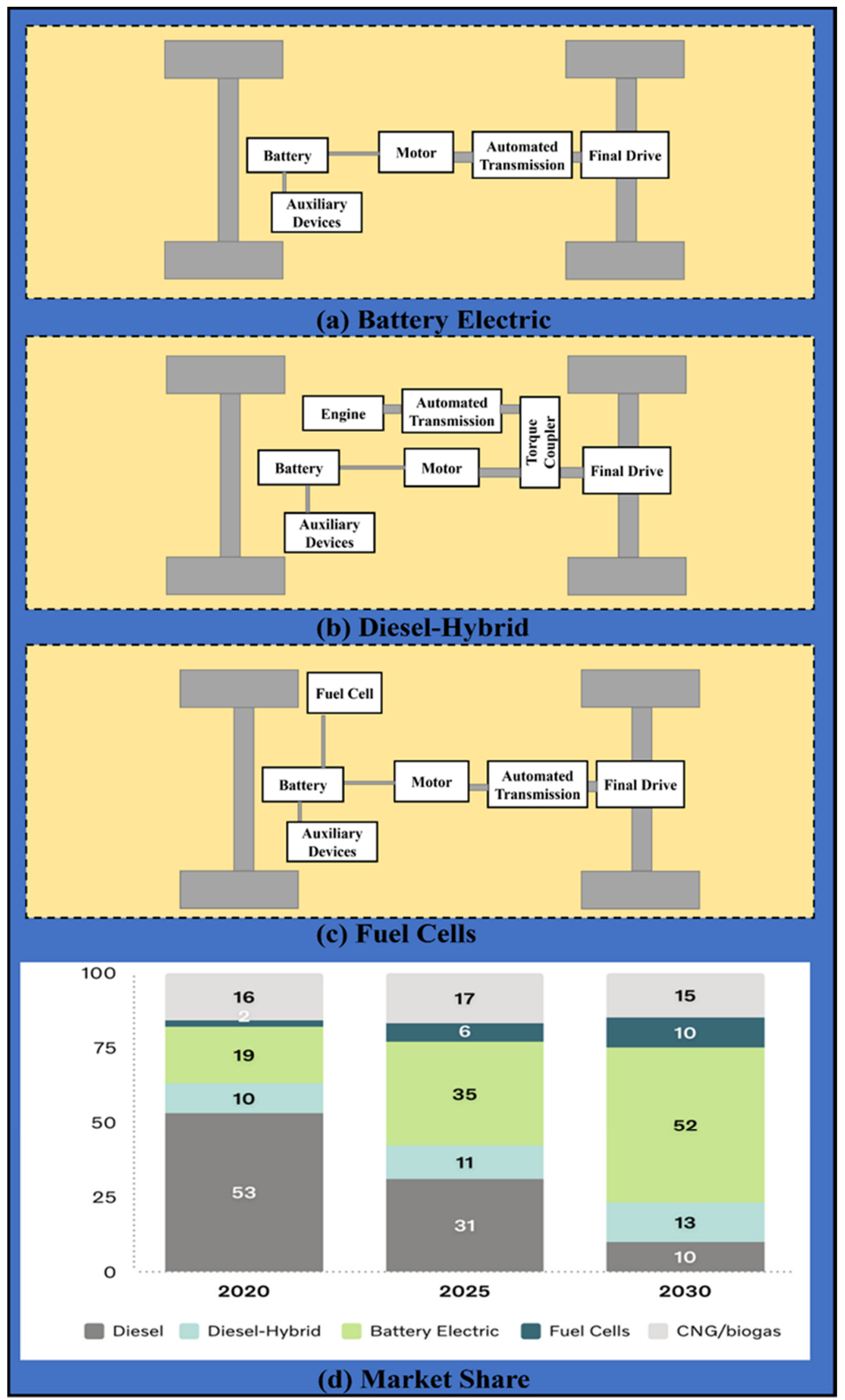

Figure 1. Global electric buses' market share according to the bus type (2020-2030): (a) BEB, (b) series hybrid electric bus (HEB), (c) parallel HEB and (d) Market Share [11]. 
Due to the operating conditions, previous studies have reported that the energy consumption of electric vehicles (EVs) can vary significantly [19]. Although EBs are highly energy-efficient, their consumption is also influenced by multiple factors, such as the passenger load, bus route characteristics, weather conditions, and driver's aggressiveness [20]. In this context, the evaluation and estimation of bus energy consumption have become a crucial precondition for the development and deployment of large electric bus fleets, and for the necessary infrastructure for charging those fleets of buses. In addition, estimation of $B E B$ energy demand is of great concern to policymakers since this estimation has a significant influence on growing BEB technologies. The effective development of BEBs is highly dependent on energy consumption methods. In a nutshell, the total energy consumption estimation of BEBs potentially impacts three domains: energy management [21-23], cost-benefit analysis [21,24], and GHG emissions [25-27].

Very few studies provide a detailed explanation of approaches to estimate the energy consumption of BEBs $[8,28,29]$. However, these studies have not classified the methods and approaches applied to estimate BEB energy consumption. Moreover, some of the previous studies on this topic have not explained the models that cover the entire bus transportation network, including big-city depot and small-town depot networks. Hence, scientists, researchers, and academics have undertaken numerous studies to improve the estimation of BEB energy consumption; however, the issues and challenges of these studies have yet to be verified. Thus, this review paper fills the gap by classifying the methods and approaches for estimating BEB energy consumption into small-town depot and big-city depot networks. This review briefly discusses the models and formulations of networks associated with well-to-wheel (WTW) assessment, which can be applied to predict the total BEB energy demand, where the main concern is to develop an effective estimation method. Furthermore, this paper briefly highlights the main challenges with recommendations concerning the estimation methods. This paper offers a detailed analysis of the published articles in order to gain knowledge on the techniques of estimation of BEB energy consumption, so it guides the researcher to select the most efficient model or algorithm. The primary goal of this work is to review current state-of-the-art electric bus energy consumption methodologies to provide direction for the future development of electric bus applications. Furthermore, the goal is to provide a comprehensive overview of the current models offered to estimate the energy consumption of electric buses using selected approaches to aid in future studies in this field. Based on WTW analyses, this paper outlines the key variables in electric bus energy consumption. It also categorizes and examines electric bus energy consumption strategies based on the modeling scale: small-town depot approaches and big-city depot methods. Moreover, this paper reviews the most recent optimization methods, which will be significant for the future development and implementation of new estimation approaches. Finally, this review will be highly useful for engineers, policymakers, and automotive manufacturers in terms of determining the applicable technique and recognizing challenges. The main contributions of this review paper can be listed as follows:

(a) A summary and critical investigation of the state-of-the-art approaches used for estimating the energy demand of BEBsare described in detail. In particular, methods used for collecting the data integrated into prediction models such as simulation, actual, and driving-cycle standards are examined. As a consequence, the reader will have a better understanding of this area.

(b) To achieve some optimal pattern parameters of BEB fleet systems, a detailed explanation of the most recent optimization methods is comprehensively reviewed. Besides, a generic framework of optimization algorithms, which includes artificial neural network (ANN) and particle swarm optimization (PSO),is proposed by the authors of this paper.

(c) The issues and challenges including the impact of external factors, replicating the real-world data, big data analytics, validity index, and bus routes topography are 
identified. Furthermore, solutions are recommended and possible suggestions on each issue are summarized.

This review is structured as follows: Section 2 presents background on BEB energy consumption according to WTW assessment. A detailed description of the estimation methods of small-town depot and big-city depot networks is discussed in Section 3. The most recent optimization methods are reviewed in Section 4. Some major issues and challenges with possible solutions are identified in Section 5. The main findings and conclusions are presented in Section 6.

\section{The Surveying Method}

This article is based on a methodological framework where various keywords were selected to search for suitable studies within the purposes and scope of this review including, battery electric buses, WTW model, energy consumption forecast, transportation networks, and data analysis. In the first stage, article titles and abstracts were screened, followed by a full article examination and comprehensive content analysis of the relevant articles. The inclusion criteria were as follows: journal articles, conference papers/proceedings and books paired with selected news articles from reputable sources, and a set of other published documents from different authorities. All the resources gathered were published in English. This study utilizes two databases (Scopus and Web of Science) and the Google Scholar search engine to track the published papers that fit the scope of this review. The findings of the former databases/search engines were paired with a set of selected news articles/published documents from reputable sources to complement the found research articles with the most up-to-date news on the estimation methods of energy consumption for battery-electric buses. A sum of 378 references was chosen after the primary search. The first assessment and screening were carried out using the appropriate keywords, title, abstract, content, and journal's main subject of interest, and accordingly, 211 references were identified. The second evaluation and screening were conducted using the articles impact factor, the review process, purpose and scope of the review, and citation. Finally, a total of 109 references were selected for review at this stage.

\section{WTW Assessment of BEB}

Well-to-wheel analysis is an assessment techniqueutilized for computing the energy from the well (or where the energy is generated) to the bus battery, and then on board the bus from the battery to the wheels (BTW), as shown in Figure 2. Concerning WTW analysis, the authors in [30] provided a method to measure the environmental effects of internal combustion engine vehicles (ICEVs) and battery electric vehicles (BEVs) using a WTW analysis. The results of this study showed that regardless of the vehicle technology or category, $\mathrm{CO}_{2}$ emissions computed using in-use consumption estimates were higher than the relevant type-approval. More specifically, when it comes to emission extraction, gasoline ICE vehicles outperform diesel. BEVs are much more environmentally beneficial than ICEVs in countries with a high proportion of renewable energy. However, BEVs release slightly less $\mathrm{CO}_{2}$ than ICEVs in countries with a high proportion of fossil fuels. The Low Emission Bus Guide is designed to give bus operators and local governments an overview of the benefits of various low emission fuels and technologies that minimize air pollution and greenhouse gas emissions. A low carbon emission bus saves more than $30 \%$ of its WTW greenhouse gas emissions when compared to an identical Euro III diesel bus of similar passenger capacity. This handbook covers the following low-emission bus technologies and fuels: alternative powertrains-electric, hybrid, plug-in hybrid, hydrogen fuel cell; gasoline spark-ignition engines; low-carbon fuels; biomethane and renewable biodiesel; Euro VI diesel buses with electric ancillaries; and selected catalytic reduction in diesel bus retrofit technology [31]. In this regard, Table 1 shows the low-carbon technology solutions in the passenger bus transport sectors by subcategory. 


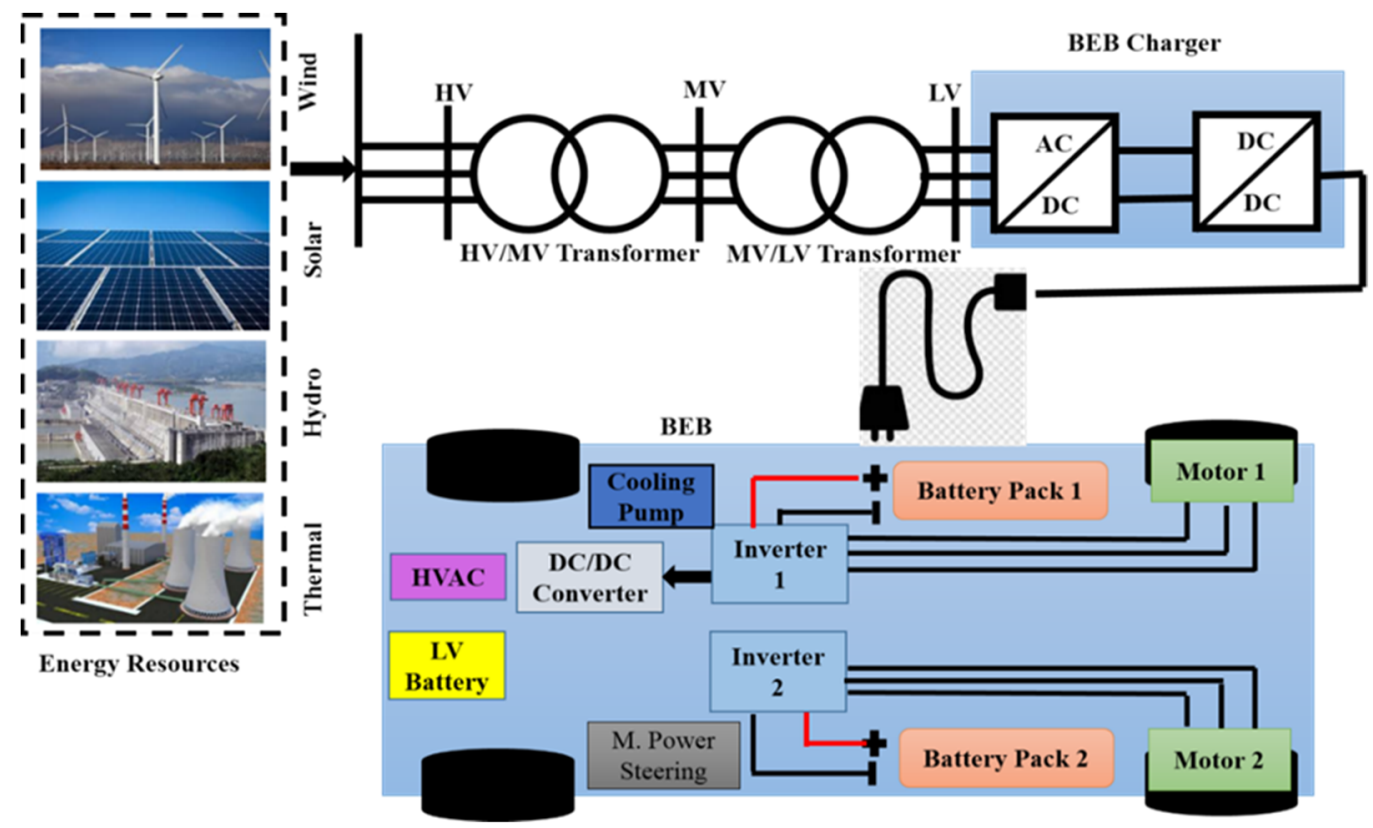

Figure 2. Block diagram of WTW assessment.

Table 1. Low-carbon technology solutions in the passenger bus transport sectors.

\begin{tabular}{cl}
\hline Category & Low-Emission Technology Choices Are Available \\
\hline Small & Battery electric vehicle and high efficient vehicle \\
Medium & Battery electric vehicle, plug-in hybrid electric vehicle, fuel-cell electric vehicle, hybrid \\
Heavy & vehicle, high efficient vehicle, compressed natural gas vehicle. \\
& Fuel-cell electric vehicle, compressed natural gas vehicle, hybrid vehicle, high efficient bus. \\
\hline
\end{tabular}

Given the pollution generated by public transport, urban public transportation, particularly urban public bus transportation is critical for implementing and increasing electromobility in transportation. According to the literature, an electric bus reduces petroleum use by $85-87 \%$ when compared to a diesel bus, resulting in a $32-46 \%$ reduction in fossil fuel use and a 19-35\% reduction in $\mathrm{CO}_{2}$ emissions over the life cycle [32]. Another study has been carried out to assess the energy and environmental performances of five various types of urban passenger bus powertrains, as well as a multiphysics index based on WTW analysis [33].It concludes that the HEV is the best option in the medium and short run. For the long-term, BEV for shorter ranges and FCHEV for all ranges appear to be viable options if the renewable generation portion of the energy mix increases sufficiently. The authors in [34] proposed a framework for comparing $\mathrm{CO}_{2}$ emissions between traditional diesel buses and BEBs. In comparison to traditional diesel buses, $\mathrm{BEBs}$ could lower $\mathrm{CO}_{2}$ emissions by 18.0-23.9 percent. WTW is also used to analyze the lifecycle vehicle energy efficiency in [35]. In this study, the consideration of power consumption for material structure was discovered to have a substantial impact on the evaluation of vehicle energy efficiency. The vehicle energy efficiency test is beneficial when using WTW analysis at many lifespan phases. WTW analysis was also utilized in [36] to evaluate the energy performance indicators across public bus systems in Sweden in different ways. The findings of this study showed that the WTW has distinct advantages in terms of emissions reductions and fossil energy use. Moreover, the challenges of environmental sustainability were investigated in [37], which showed that customer behavior still has a large role in rebound effects.

\subsection{Wheel to Battery (WTB) Assessment}

WTW tools can be used to analyze and evaluate the economic cost, energy consumption, and environmental impact of EBs. The objective of this paper is to analyze the energy 
consumption of EBs by using WTW tools, which consists of three parts as follows: (a) production of electricity: this section examines the average efficiency of the net electricitygenerating plant and energy, which includes the cost of primary fuel transportation and extraction as well as the cost of pumping losses; (b) transformation, transport, and distribution: this section looks at low voltage losses and transformation efficiency in the context of transport, distribution, and transformation systems; and (c) the charging station: the bus battery charge box takes into account the total efficiency of the charging methods that have been examined. The failure to account for efficiency differences under various situations may result in increased electric losses, and as a result, higher operating expenses during operations [38]. Power losses are particularly problematic for high-duty cycles, such as GBI functions. Likewise, when charging electric buses, power losses occur in the power grids and the charging stations supplying the buses. Therefore, a WTB assessment is required to evaluate the losses of energy throughout the process of bus charging with the electricity transmission. To achieve WTB assessment, power flow analysis, which yields the power losses, is essential [39]. When considering the BEB charging stations, the transformers and lines in the charging stations of BEBs are taken into consideration. BEB charging stations are supplied with alternating current, and the voltage is adjusted to the desired level by utilizing a DC/DC converter such as (a) a transformer that converts high to medium voltage (HV/MV); (b) a transmission line with a medium voltage; and (c) a transformer that converts medium voltage to low voltage (MV/LV). A three-phase rectifier and a DC/DC converter are included in the charger system [40]. Transmission system power losses can be calculated as follows:

$$
\Delta P=P_{T}\left[1-\prod_{i=1}^{n} \eta_{i}\right]
$$

wherethe transmission system power losses are denoted by $\Delta P(\mathrm{~kW})$, the output power is denoted by $P_{T}(\mathrm{~kW}), \eta_{i}$ is the power supply network's efficiency for parameter $i$, and $n$ denotes the number of power supply network elements. The transmission system's energy losses, $\Delta E(\mathrm{kWh})$, are calculated using the following formula:

$$
\Delta E=(\Delta P) T
$$

where $\Delta P$ represents the loss of power in the transmission lines in $\mathrm{kW}, \Delta E$ represents the energy losses in $\mathrm{kWh}$, and $T$ is the time taken to draw electrical energy from transmission lines during a day, in seconds (s).

\subsection{WTW Energy Efficiency}

Electricity efficiency varies greatly depending on how it is generated. When it comes to efficiency, renewable energy-based production is the best option. A fifty percent efficiency is achieved by using the natural gas combined cycle (NGCC) and the coal supercritical steam cycle (USC) [41,42]. An average of $40 \%$ of the efficiency comes from using a mix of production methods such as those used most commonly in Europe [41]. The ratio between the net volume of energy generated and the energy used throughout the process is used to calculate the WTT energy efficiency. One mega-joule (1 MJ) of fuel or energy in the form of liquid, gas, or electricity is frequently used as the functional unit in the WTT stage [43]. However, oil-based fuel remains the most efficient source of energy on a WTT basis, based on current energy production technologies, with an average of $3.82 \mathrm{MJ} / \mathrm{km}$, followed by hydrogen $(7 \mathrm{MJ} / \mathrm{km})$ and electricity $(11.90 \mathrm{MJ} / \mathrm{km})$. However, when it comes to natural resources and energy security, renewable energy-based power is perhaps the most efficient, and therefore desirable, form of energy [44-46]. Based on [8,41], TTW energy consumption is commonly measured in diesel equivalent miles per gallon (mpg) or megajoules per kilometer $(\mathrm{MJ} / \mathrm{km})$. On a TTW basis, BEB has the highest energy efficiency, with $6.76 \mathrm{MJ} / \mathrm{km}$ of fuel consumption, followed by FCEB $(10.48 \mathrm{MJ} / \mathrm{km})$ and series HEB (10.81 MJ/km). 


\section{Estimating BEB Energy Consumption: The Main Approaches}

To develop a BEB fleet and carefully choose the optimum battery size, the energy consumption based on each bus route has to be considered during the day and in associated with various traffic conditions. Researchers usually apply one of the following methods to compute the energy consumption for BEBs. These approaches are classified into two groups: small-town depot networks and big-city depot networks based on the theory of complex networks. According to this theory, a bus network can be categorized into different types (small-town depot, big-city depot, and random) depending on their statistical characteristics such as average path length, clustering coefficient, and degree distribution. More detailed descriptions of this classification can be found in [47].

\subsection{Small-Town Depot Approaches}

Networks with high clustering coefficients and a short average distance are known as small-town depot networks. A scale-free network follows the power-law distribution in terms of node degree distribution [48,49]. In bus transportation networks, Xiping et al. [47] investigated the spatial characteristics of bus service networks in Shenzhen, China by using the spatial units of traffic analysis zones (TAZs) associated with bus numbers. They concluded that the bus service network of Shenzhen represents a small-town depot network. TAZs with a high clustering coefficient, as shown in Figure 3, are generally found on the outskirts of cities, in environments such as forests, mountains, and farms that are sparsely populated. Several previous studies have applied one of the following three approaches for estimating the BEB energy consumption in small-town depot networks.

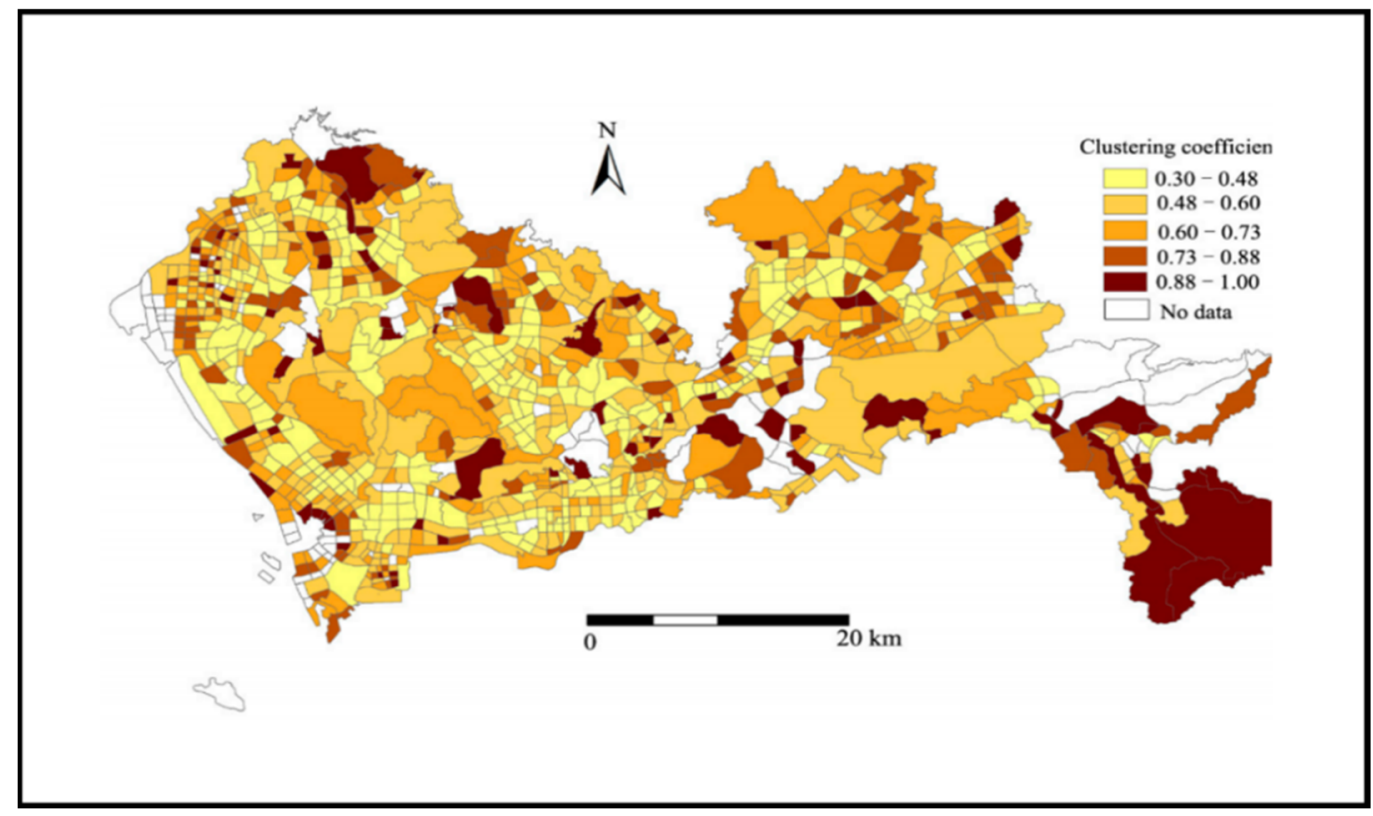

Figure 3. Spatial distribution of the clustering coefficient [47].

\subsubsection{Simulation Approach}

The energy consumption model can be demonstrated by using a simulation method based on details of the driving cycles. Thus, a custom driving cycle that contains a table with velocity, grade values, scheduling times, and bus route characteristics is interpolated via a user to comply with a simulator. In this approach, a simulator tool is applied to determine the energy demands of a traveling bus. This approach is often used to compute the instantaneous energy consumptionof BEBs. The computational simulation models to calculate the energy consumption have become a significant measure in the development of new BEBs because actual testing and prototyping require more time and cost. A variety of simulation software packages (especially MATLAB-based tools) can be applied in this 
approach. For example, in a case study in Daegu Metropolitan City, the authors proposed a comprehensive plan to contribute to the adoption of electric buses in South Korea. By considering the electric motor characteristics and bus drive cycles, the ADVISOR simulator was utilized in this plan for analyzing the charging time, selecting the proper charging type, determining the energy consumption, and calculating the optimum capacity of battery energy storage [50]. Additionally, a strategy to comparethe energy usage of an EB with the performance of a similar diesel bus was implemented by using the Powertrain Simulation Analysis Toolkit (PSAT) [51]. Thus, a method to predict the energy demand of an electric bus by using PSAT was suggested, where the simulation run was compiled according to the operational performance of an actual run in Oshawa city routes in Canada [50,51].

\section{Required Data for a Simulation Approach}

To determine the BEB energy demand by using the simulation approach, a simulated dataset is required. This dataset can be presented according to time-dependent examination (temporal data), geographical segmentation (spatial data), and volume of traffic (VoT) (spatial-temporal data) [52]. In geographical segmentation, data is collected individually based on each bus route section, such as the number of bus stops and the distance between bus stops. For example, the data from the real bus diagram were used to perform the simulation by applying the k-Greedy algorithm, where these data were combined with four bus routes including bus stops in inner-city routes in Japan to compute the energy consumption by buses on the various lines [53]. A simulation tool was applied to create an energy model for electric buses in the Ohio State University in the United States by using a dataset for one of the bus routes, where the spatial data was classified among different bus stops into urban and suburban [14]. A time-dependent analysis refers to the temporal dataset based on the journey time of a bus, which includes idling time, dwell time, and the frequency it reaches per hour of travel time. In a case study in Penghu, Taiwan, the authors in [54] proposed a model for analyzing the energy consumption and cost-benefit of comparing the existent bus transportation network with the BEB transportation network by examining the effects of day and nighttime. In contrast, the VoT is a function of both timedependent segmentation and geographical data. In the case of Stockholm, for example, the quantitative simulation results of energy consumption with various bus routes were obtained by using the bus network data based on the temporal and spatial characteristics of the bus lines [55].

\section{Simulation Models}

To simulate a BEB powertrain that can be used for the analysis of its energy consumption, two main models are identified: forward and backward modeling. Models that compute the BEB energy demand by using bus characteristic data and drive cycles while ignoring the dynamic of the bus components and driver behavior are called "backward models". In the case of the forward models, throttle and braking commands associated with the driver behavior, which highly affects the energy use, are considered [56-58]. A variety of MATLAB/Simulink tools could be applied to compute BEB energy consumption based on forward and backward modeling. For example, Rios [59] presented a BEB simulator model to determine the energy consumption by using MATLAB/Simulink tools under different driving routes and parameter configurations, as shown in Figure 4. Furthermore, a framework tool in [60] was developed based on a simulation model to evaluate energy consumption. The authors reported simulated values for the energy consumption of an EB ranging from 1.24 to $2.48 \mathrm{kWh} / \mathrm{km}$ in a case study of two European cities. A surrogate model was proposed in [28] to predict the energy consumption of city EBs by using the UQLab toolbox for MATLAB. 


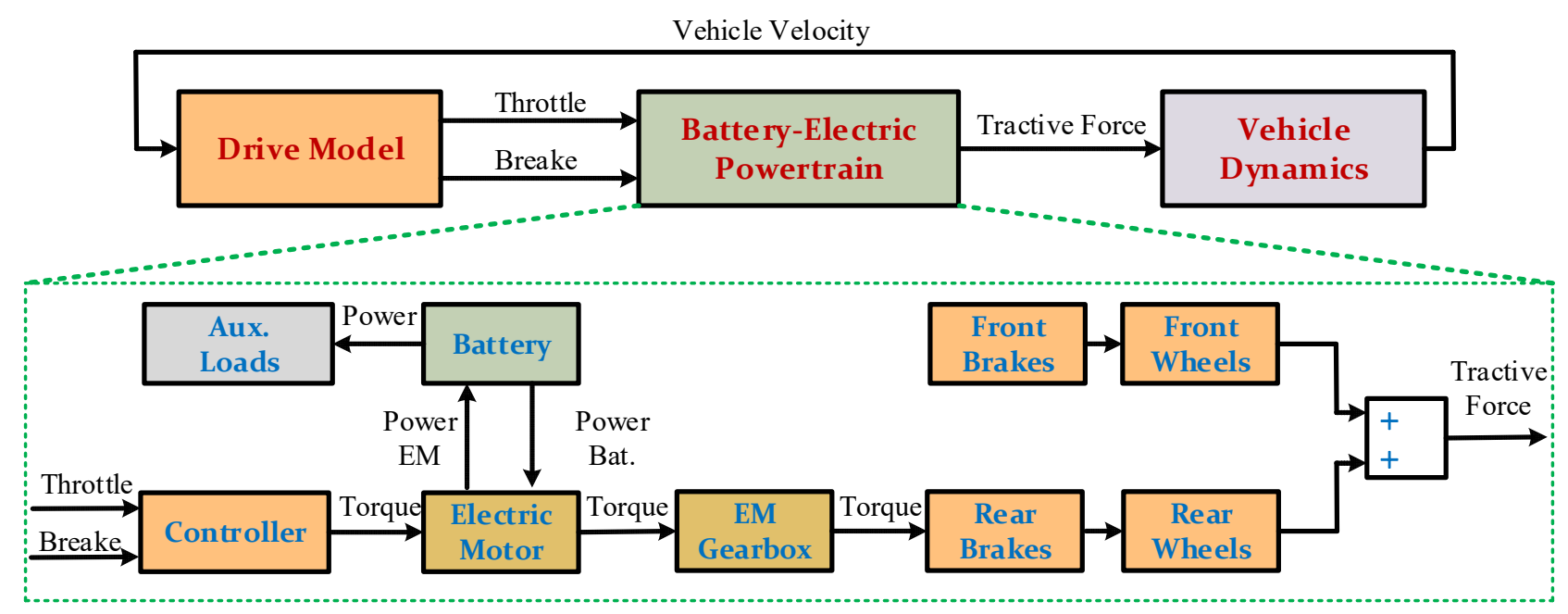

Figure 4. Composition of the BEB simulator model [59].

\subsubsection{Actual-Measurement Equipment}

In order to estimate a highly accurate value for BEB energy consumption, measurement equipment can be built to absorb the energy consumption associated with a high spatialtemporal resolution. The core of the energy consumption models in this approach is the design of measurement devices and the use of one or more specific driving cycles to acquire real-world measured data. Real data from the field are captured for predicting yearly, monthly, and weekly energy consumption via the bus services' trips or the bus prototypes by using specific models. As a result, the estimated energy demand can be used to identify the feasibility of the parameters that are planned for future BEB operation, which includes battery size, required charging power, and the infrastructure strategy.

\section{Required Data of Actual-Measurement Equipment}

Data-driven models of actual measurements are derived by identifying statistical relationships in sets of real-world data. However, the quality of the model depends heavily on the available data, and the accuracy is not ensured when the model is used to extrapolate outside the range of the available data. It is possible to acquire dynamic traction and consumption data on a test bench and the open road by employing an experimental object. A real velocity profile of a $12 \mathrm{~m}$ urban transient bus in Berlin-Germany was recorded by simultaneously using a Global Navigation Satellite System sensor. Besides this velocity profile, the battery state of charge (SOC) and auxiliary power were measured to implement the energy consumption model $[61,62]$. By using Internet of Things (IoT) technology integrated into the Global Positioning System, six BEBs were measured in three bus lines located in southern Finland to accurately estimate the BEB energy consumption. The data for these measurements were sent to cloud computing technology to be saved in an IoT cloud server [63].

\section{Real-World Performance}

The real-world performance can be divided into two approaches: a current city bus fleet (CCBF) and a developed BEB prototype (DBEBP). In the CCBF model, the realworld data for bus routes are generated based on a measurement of several transit bus networks, which can be collected over time, where these buses are powered by diesel fuel. As described in Figure 5, a developed framework tool based on the CCBF model was presented by Gao et al. [18]. In this framework, city transit electric buses' energy consumption was evaluated based on real-world operational routes and schedules to assess the feasibility of bus electrification for public transit services. A testbed of a 12-m city bus that operated with a powered diesel engine was used with a developed mathematical model to estimate the energy consumption of an electric bus [64]. By using this testbed, the 
generated real-world data was collected according to the actual bus route with a length of $100 \mathrm{~km}$, by applying a standardized test procedure known as the Braunschweig city driving cycle.

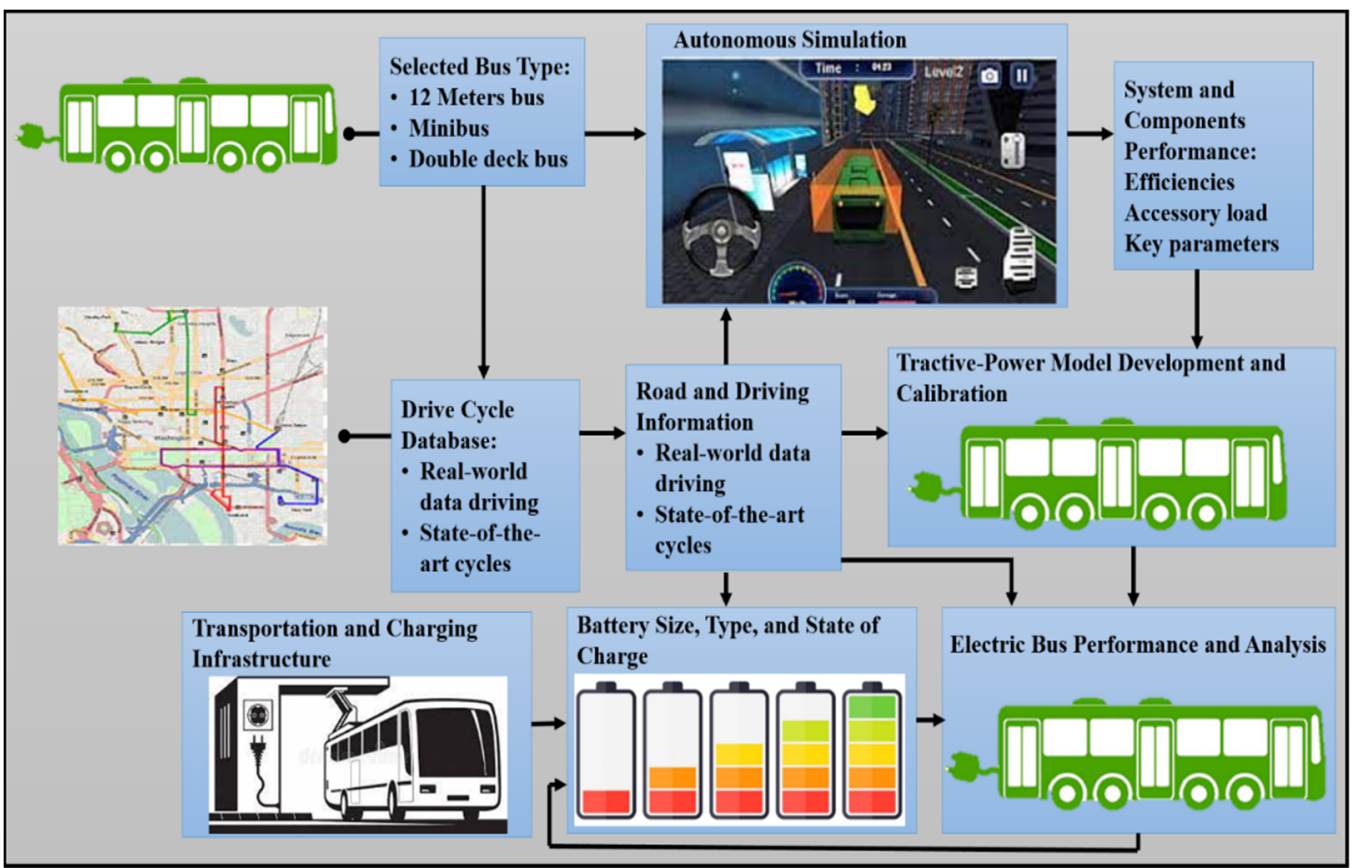

Figure 5. The framework tool for bus electrification feasibility based on actual prototype [18].

In the DBEBP approach, a BEB prototype is operated to be tested in a specific area, followed by laboratory testing to determinethe driving-cycle dependence and energyconsumption values. For example, the authors in [65] presented the fundamental setup of an EB test platform in Finland based on a prototype EB called the "test mule."This prototype was equipped with data-logging devices and related sensors to monitor real-life energy usage and the impact of weather conditions on the functioning of the vehicle and subsystems. In Macao, a BEB prototype ( $8 \mathrm{~m}$ bus) was developed to measure the value of energy consumption under conditions of maximum air conditioning and load [15]. Some of the actual models are presented in Table 2 in order to estimate the energy consumption of electric city buses in different countries.

Table 2. Number of actual models according to different countries.

\begin{tabular}{|c|c|c|c|c|c|}
\hline Ref. No. & Collected Data & $\begin{array}{c}\text { Model } \\
\text { Description }\end{array}$ & $\begin{array}{c}\text { Case Study } \\
\text { (State/Country) }\end{array}$ & $\begin{array}{l}\text { Estimated Energy } \\
\text { Consumption }\end{array}$ & $\begin{array}{c}\text { Specific } \\
\text { Contributions }\end{array}$ \\
\hline [18] & $\begin{array}{l}\text { The data were collected } \\
\text { from conventional diesel } \\
\text { buses to present } \\
\text { real-world routes } \\
\text { driven. }\end{array}$ & $\begin{array}{l}\text { A framework tool } \\
\text { was established to } \\
\text { relate feasibility for } \\
\text { bus electrification } \\
\text { with real-world } \\
\text { vehicle } \\
\text { performance, } \\
\text { reliability of city } \\
\text { transport services, } \\
\text { charging } \\
\text { infrastructure, and } \\
\text { battery sizing. }\end{array}$ & $\begin{array}{c}\text { Knoxville Area } \\
\text { Transit (KAT) is a } \\
\text { public } \\
\text { transportation } \\
\text { system in } \\
\text { Knoxville, } \\
\text { Tennessee, United } \\
\text { States. }\end{array}$ & $\begin{array}{l}\text { The average } \\
\text { battery } \\
\text { consumption of an } \\
\text { electric bus is } 1.35 \\
\text { kWh per kilometer. }\end{array}$ & $\begin{array}{l}\text { The tool of the } \\
\text { developed } \\
\text { framework can } \\
\text { flexibly adopt } \\
\text { various charging } \\
\text { schedules, battery } \\
\text { technology data, } \\
\text { and different } \\
\text { routes. }\end{array}$ \\
\hline
\end{tabular}


Table 2. Cont.

\begin{tabular}{|c|c|c|c|c|c|}
\hline Ref. No. & Collected Data & $\begin{array}{c}\text { Model } \\
\text { Description }\end{array}$ & $\begin{array}{c}\text { Case Study } \\
\text { (State/Country) }\end{array}$ & $\begin{array}{l}\text { Estimated Energy } \\
\text { Consumption }\end{array}$ & $\begin{array}{c}\text { Specific } \\
\text { Contributions }\end{array}$ \\
\hline$[65]$ & $\begin{array}{l}\text { Tests were conducted } \\
\text { using two routes based } \\
\text { on actual data, each } \\
\text { about } 100 \mathrm{~km} \text { long in } \\
\text { New York in thecenter } \\
\text { of Manhattan. }\end{array}$ & $\begin{array}{l}\text { Testing was } \\
\text { performed using } \\
\text { standard test } \\
\text { cycles for heavy } \\
\text { vehicles and roads } \\
\text { based on real } \\
\text { traffic conditions. }\end{array}$ & Finland & $\begin{array}{c}\text { Energy } \\
\text { consumption is } \\
170-200 \text { kWh for } \\
10 \mathrm{~h} \text { of operation. }\end{array}$ & $\begin{array}{l}\text { A computational } \\
\text { tool was } \\
\text { developed to } \\
\text { support } \\
\text { operational } \\
\text { planning and route } \\
\text { for BEBs. }\end{array}$ \\
\hline [15] & $\begin{array}{c}\text { To assess their on-road } \\
\text { energy consumption, } \\
\text { they used on-board } \\
\text { diagnostics (OBD) data } \\
\text { collectors and a local } \\
\text { power company billing } \\
\text { monitoring system } \\
\text { under a variety of } \\
\text { operational settings (e.g., } \\
\text { load mass, traffic } \\
\text { conditions, and AC } \\
\text { usage). }\end{array}$ & $\begin{array}{l}\text { As part of the } \\
\text { demonstration } \\
\text { effort, three } \\
\text { different BEB } \\
\text { models were put } \\
\text { through their paces } \\
\text { on public roads. }\end{array}$ & Macao/China & $\begin{array}{c}\text { For an } 8.8-\mathrm{km} \text { trip, } \\
\text { the battery } \\
\text { consumes } 15.3 \\
\text { kWh of electricity, } \\
\text { which includes the } \\
\text { EVSE and battery } \\
\text { charg- } \\
\text { ing/discharging } \\
\text { (C/D) losses. }\end{array}$ & $\begin{array}{l}\text { The BEBs have } \\
\text { proven to be a } \\
\text { good replacement } \\
\text { for diesel buses in } \\
\text { mega-city } \\
\text { downtown regions, } \\
\text { according to the } \\
\text { project's results. }\end{array}$ \\
\hline
\end{tabular}

\subsubsection{Driving-Cycle Standards}

For testing the configuration of the electric bus drive system, a bus route driving-cycle standard is used as a reference module. This module is configured to work with pre-made files that define the test cycles needed to estimate the electric bus's energy usage [66,67].

This section reviews several driving-cycle standards that can be adopted in this approach. A series of data points is the core methodology for these standard cycles. In this context, detailed traffic measurementsin diverse districts associated with the values of a BEB energy demand are globally accessible and can be implemented in further studies around the world. Thus, an EB manufacturer can better understand vehicle behavior by analyzing BEB performance. Thus, the driving-cycle standards adopted with the analysis of the BEB performance can help an electric bus manufacturer to estimate the required energy demand of its developed bus $[9,68]$.

\section{Required Data of Driving-Cycle Standards}

Various international organizations have created testing standards such as [69], DieselNet [70], the EU [71]), and the World Forum for Harmonization of Vehicle Regulations (WP.29)has approved their use [72]. The current value of the road's slope and elevation profile as a function of distance from the starting point or vehicle speed on a certain segment of the route are included in the details of these standards. However, the authors of cited studies mostly used a driving-cycle standard match to the conditions in their study area. The characteristics of different driving bus cycles are presented in [73]. In addition, the Federal highway driving schedule, the urban dynamometer driving schedule, and the US06 driving cycles can be used to estimate the energy consumption of an electric bus [59]. The International Association of Public Transport established a standard, namely, standardized on-road test cycles. Based on urbanization potential, this standard is divided into three groups easy urban (SORT 2, $18 \mathrm{~km} / \mathrm{h}$ ), heavy urban (SORT 1, $12 \mathrm{~km} / \mathrm{h}$ ), and suburban (SORT $3,25 \mathrm{~km} / \mathrm{h}$ ), where these standards can be applied to estimate the energy consumption on actual bus lines [74].

\section{Comparison Models}

Characteristics of various driving-cycle standards, which include different parameters such as the bus type, driving time, average speed, line length, number of bus stops, and 
required energy, have been examined by Vilppo and Markkula [17]. The study of these characteristics helped them to use one of the examined standards that has a similar number of bus stops to the city where their research was developed. However, some important parameters were not considered in their study, such as traffic conditions, particularly during peak hours. The attributes of six driving cycle standards, namely, E11, BR, MAN, Line 18, H550, and Line 51B were analyzed by the researchers in [75].

The main shortcomings of driving-cycle standards were identified by Nylund et al. [66]. They observed that the performance of several driving cycles might be inconsistent with real-world conditions, notably for bus services, due to buses' low average speed, frequent stops, and rapid acceleration/deceleration after/before arriving at a stop. Energy consumption models based on driving-cycle standards are presented in Table 3.

Table 3. Energy consumption models according to driving-cycle standards.

\begin{tabular}{|c|c|c|c|c|c|}
\hline Ref. No. & Collected Data & Model Description & $\begin{array}{c}\text { Case Study } \\
\text { (State/Country) }\end{array}$ & $\begin{array}{l}\text { Estimated Energy } \\
\text { Consumption }\end{array}$ & $\begin{array}{c}\text { Specific } \\
\text { Contributions }\end{array}$ \\
\hline [17] & $\begin{array}{l}\text { Characteristic of } \\
\text { driving cycles of } \\
\text { Braunschweig and } \\
\text { EspooL11 }\end{array}$ & $\begin{array}{l}\text { Proposed a method } \\
\text { for assessing the } \\
\text { economic viability of } \\
\text { electric buses in a } \\
\text { medium-sized city. }\end{array}$ & $\mathrm{N} / \mathrm{A}$ & $\begin{array}{c}\text { The highest usage } \\
\text { with a } 4 \mathrm{~kW} \text { heat air } \\
\text { source pump would } \\
\text { be approximately } 0.2 \\
\mathrm{kWh} / \mathrm{km} .\end{array}$ & $\begin{array}{l}\text { Oversizing the } \\
\text { battery of BEBs in a } \\
\text { mid-sized city was } \\
\text { examined based on } \\
\text { the economic } \\
\text { feasibility. }\end{array}$ \\
\hline [75] & $\begin{array}{c}\text { Energy } \\
\text { Consumption } \\
\text { characteristics of } \\
\text { the Braunschweig } \\
\text { and Espoo L11 } \\
\text { trial e-bus. }\end{array}$ & $\begin{array}{l}\text { In this study, buses } \\
\text { of } 12 \text { min length were } \\
\text { compared in } \\
\text { Tampere City } \\
\text { Transportation } \\
\text { (TKL). The average } \\
\text { consumption of } \\
\text { diesel buses was } \\
401 / 100 \mathrm{~km} \text { which } \\
\text { was used in the } \\
\text { estimation. }\end{array}$ & $\begin{array}{c}\text { Tampere } \\
\text { city/Finland }\end{array}$ & $\begin{array}{l}\text { The overall energy } \\
\text { consumption of the } \\
\text { e-bus ( } 9000 \mathrm{~kg} \text { curb } \\
\text { weight) used in the } \\
\text { calculations was } \\
\text { estimated to be } \\
\text { approximately } 1 \\
\mathrm{kWh} / \mathrm{km} \text {. }\end{array}$ & $\begin{array}{l}\text { The carbon dioxide } \\
\text { emissions and } \\
\text { lifecycle costs of } \\
\text { different types of city } \\
\text { buses wereevaluated }\end{array}$ \\
\hline [13] & $\begin{array}{l}\text { Standard Central } \\
\text { Business District } \\
\text { driving cycle. }\end{array}$ & $\begin{array}{l}\text { The longitudinal } \\
\text { dynamics model } \\
\text { calculates the energy } \\
\text { use of an electric bus } \\
\text { that operates on a } \\
\text { combination of } \\
\text { urban and suburban } \\
\text { driving on different } \\
\text { routes. }\end{array}$ & $\begin{array}{c}\text { Ohio State, United } \\
\text { States }\end{array}$ & $\begin{array}{c}1.60 \mathrm{kWh} \text { per mile is } \\
\text { the average energy } \\
\text { consumption. }\end{array}$ & $\begin{array}{l}\text { The developed } \\
\text { model could further } \\
\text { be applied to } \\
\text { investigate the } \\
\text { feasibility of } \\
\text { deploying EB fleets } \\
\text { in other settings. }\end{array}$ \\
\hline
\end{tabular}

\subsection{Big-City Depot Approaches}

In bus transportation networks, the term "big-city depot" is used by many researchers to define the bus lines for an entire country or a large city. For example, Gallet and Massier used big-city depot public transport networks to describe the entire bus routes used in the public transport system in Singapore [29]. Moreover, Amiripour and Avishaithelabeled the public bus transport of Mashhadin, Iran, which contains a bus network of 756 nodes and 1204 links, as a big-city depot network [76]. Previous researchers have typically applied one of the following methods to estimate the energy demand for BEBs in big-city depot networks.

\subsubsection{Longitude Dynamics Model (LDM)}

This section provides a detailed review of the most recent LDM technique, which would be used to estimate the energy consumption of big-city depot bus networks. In 
addition to this, the mathematically formulated LDM is discussed in detail for the further extension of research. In this context, LDM refers to the bus's longitudinal dynamics, adapted with powertrain characteristic effects based on actual power flow, which uses the dynamics of the bus to finally calculate the required energy demand of the battery packs. Therefore, the energy consumption of a big city depot bus network can be predicted by using LDM accordingly, with real-world data [29]. For example, in a case study conducted in Aachen-Germany, Sinhuber et al. [77] developed an LDM, where the real-world data was generated by applying waypoints (geocoordinates) technology. Moreover, the authors of [54] presented a longitude dynamics model in order to estimate the total energy demand of electrifying urban buses in Berlin, Germany. As shown in Figure 6, the total required driving force $\left(F_{x}\right)$ describes the bus movement, which can be expressed according to Newton's second law based on four forces, as follow:

- $\quad$ Aerodynamic Drag force $\left(F_{a}\right)$

It is possible to model aerodynamic drag as:

$$
F_{a}=\frac{1}{2} P C_{d} A(v-w)^{2}
$$

where the aerodynamic drag coefficient $\left(C_{d}\right)$ is a function of the relative wind direction, when driving at high velocities, the influence of the relative wind direction is reduced. In this context, it is possible to determine $C_{d}$ by using computational fluid dynamics (CFD) whereas, $p$ is the density of air in $\mathrm{kg} / \mathrm{m}^{3}$ and the value of $p$ changes with variations in humidity and temperature. $A$ denotes the bus's frontal cross-sectional area in square meters, and $w$ denotes the wind speed in meters per second in the bus' driving direction.

- $\quad$ Rolling Resistance Force $\left(F_{r}\right)$

The rolling resistance force is caused by the continuous deformation at the tire-road contact patch of the rolling pneumatic tire. Due to the visco-elastic nature of the rubber in the tire, energy is lost in this process, resulting in a resistance force:

$$
F_{r}=C_{r} M_{g} \cos \phi
$$

The rolling resistance coefficient is denoted by the symbol $C_{r} ; M$ in kgis the total mass (bus mass and passengers' weights), $g$ is the acceleration due to gravity $9.81 \mathrm{~m} /\left(\mathrm{s}^{2}\right)$, and $\phi$ is the angle of inclination in (rad).

- Grade Force (F_s)

As illustrated in Figure 6, it can be seen that the road gradient influences energy consumption, where grade force can be expressed by the following equation:

$$
F_{s}=M_{g} \sin \phi
$$

- $\quad$ Transient Force $\left(F_{t}\right)$

The transient force is required for accelerating or retarding the bus, as follow:

$$
F_{t}=\left(M+m_{f}\right) \frac{d v}{d t}
$$

where $\left(m_{f}\right)$ denotes the imaginary mass of rolling inertia in kilograms.

- $\quad$ Driving Force $\left(F_{x}\right)$

As a result, the driving force of the bus can be expressed as:

$$
\begin{gathered}
F_{x}=F_{r}+F_{s}+F_{a}+F_{t} \\
F_{x}=C_{r} M_{g} \cos \phi+M_{g} \sin \phi \frac{1}{2} p C_{d} A(v-w)^{2}+\left(M+m_{f}\right) \frac{d v}{d t}
\end{gathered}
$$


Therefore, the driving force of the bus can be expressed as:

$$
F_{x}=\eta \frac{P_{d c}}{F}
$$

where $\eta$ is the overall powertrain efficiency between battery and wheels, $P_{D C}$ is the electrical DC power drawn from the battery by the powertrain and $v$ is the vehicle velocity. The total needed mechanical energy at the wheels can be stated in the vehicle dynamics equation using Equations (8) and (9) as a function of the kinematic parameters governing bus movement, as follows:

$$
E=\frac{\eta}{3600}\left[\left(M_{g} C_{r} \cos \Phi\right)+M_{g} \sin \Phi+\left(\frac{1}{2} p A C_{d}(v-w)^{2}\right)+\left(\left(M+m_{f}\right) \frac{d v}{d t}\right)\right] d
$$

In this case, $E$ represents the mechanical energy required at the wheels to move a distance (d) in kilometers.

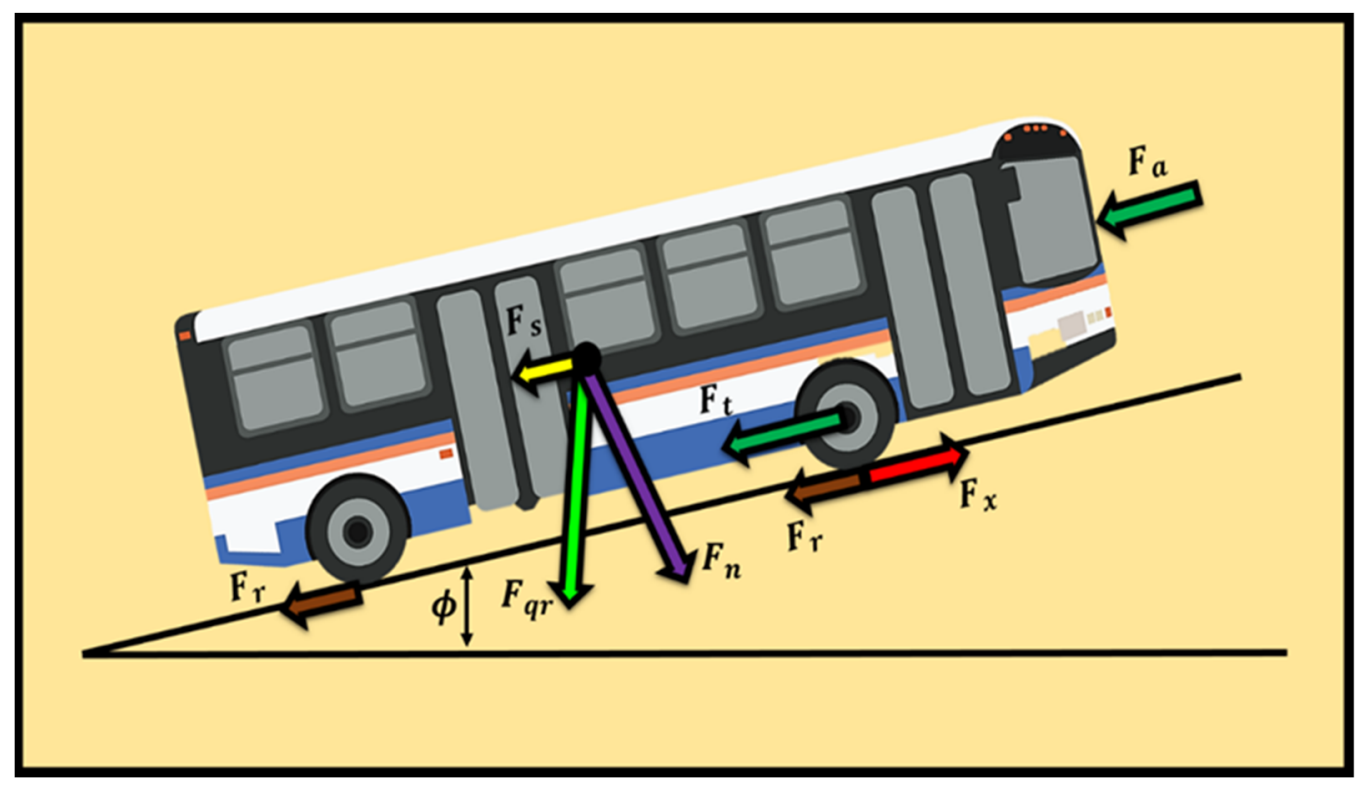

Figure 6. The total required driving force of a BEB.

\subsubsection{Machine Learning Methods for Predicting Energy Consumption of BEBs}

The term machine learning refers to computer algorithms that can learn from their input features followed by layers of learning, testing, and a validation process. Machine learning models can be divided into learning techniques known as unsupervised learning and supervised learning [78]. In this context, the supervised learning models could be used to predict targets for unseen samples by training enough data and creating a relationship between the features of input data. In recent decades, various supervised learning algorithms have been developed in transportation sectors, particularly for the estimation of energy consumption of electric buses [7]. The general block diagram of the supervised learning algorithm for estimating the energy consumption of BEBs is illustrated in Figure 7. In contrast, unsupervised learning is generally used to cluster the input of unlabeled data by applying hidden patterns and similarities in underlying features. 


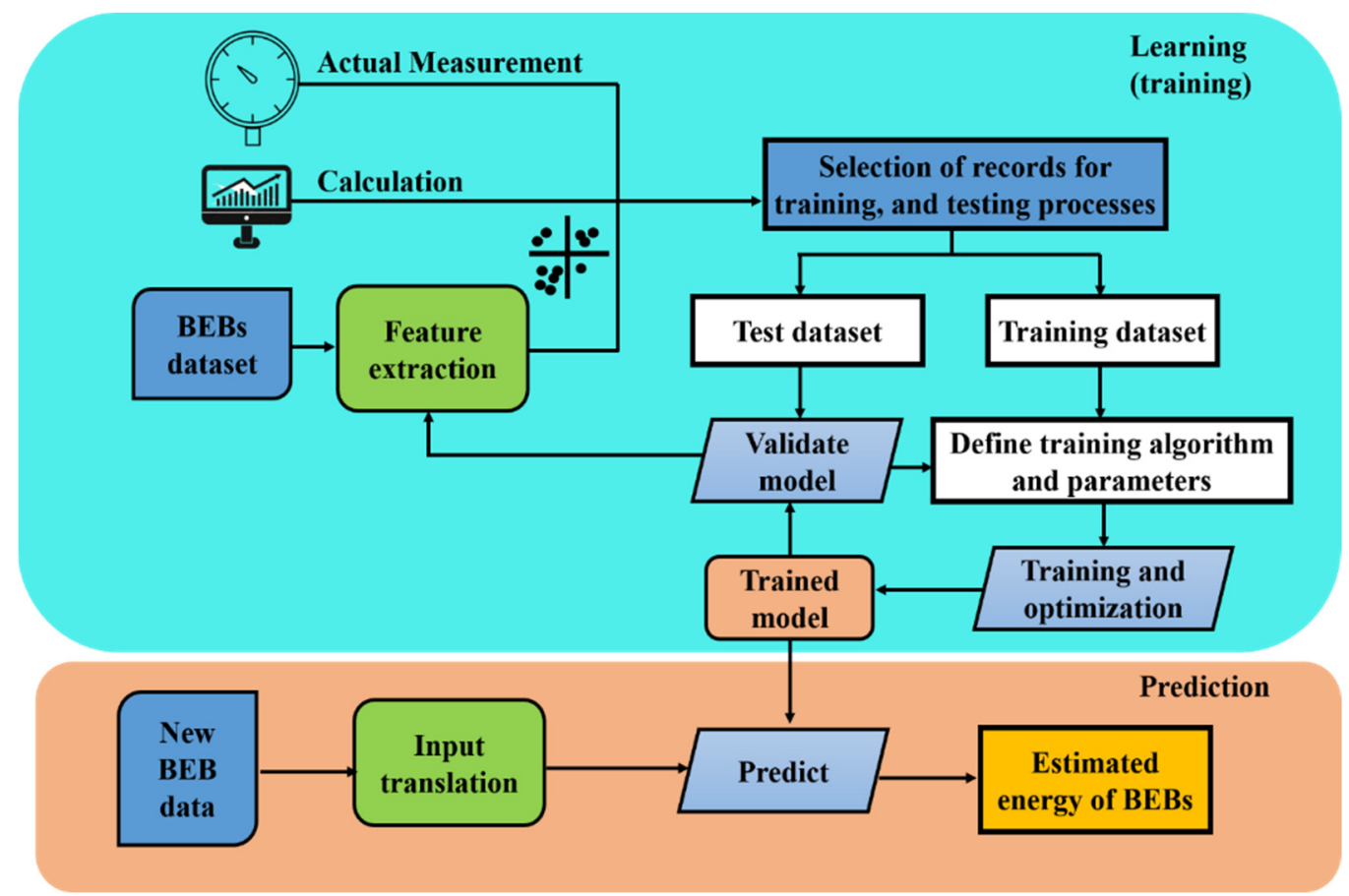

Figure 7. General scheme diagram of a supervised learning algorithm for estimating the energy consumption of BEBs.

Some typical algorithms have made rapid progress because of advances in advanced machine learning techniques and high-performance computing such as radial basis function neural network [79], wavelet neural network (WNN) [80], neural network-based generalized growing and pruning radial basis function [81], and NN-based learning models [82] have been employed to estimate the energy consumption of big-city depot bus networks. In this respect, two parameters are used to determine the energy consumption for each bus route segment in the energy prediction model. The first element is expected energy consumption based on the amount of energy required to drive along the same road stretch previously. The second aspect is the additional energy consumption that may occur as a result of unanticipated traffic situations in the future [83,84]. High-resolution data for the buses' driving profiles are required for machine learning methodologies. The physical equations approach is designed to overcome situations in which high-resolution data are unavailable, rather than relying on oversimplified estimates that ignore real-world trip features. The common longitudinal dynamics formulation is used in this model for BEB fleets. It has been modified to eliminate the need for high-resolution velocity profile readings. It only requires records of bus arrival and departure times at each stop.

\section{Optimization Methods}

Optimization methods can be applied to achieve an optimal solution for a specific objective function by maximizing or minimizing its value, as discussed in detail in [85,86]. In this paper, the suggested optimization models could be applied to achieve the optimal pattern parameters of BEB fleet systems, such as the bus battery capacity, chargers rated power and the total number of installed chargers in the charging station. The goal of the optimization issue is to reduce the cost of electrification for bus transit networks. It also includes precise energy consumption modeling for the $\mathrm{BEB}$, which takes into account route topology, bus models, and traffic circumstances. A schematic overview of a BEB optimal configuration based on energy consumption is presented in this section. As shown in Figure 8, different approaches could be utilized for optimization tasks; these approaches could be categorized as follows. 


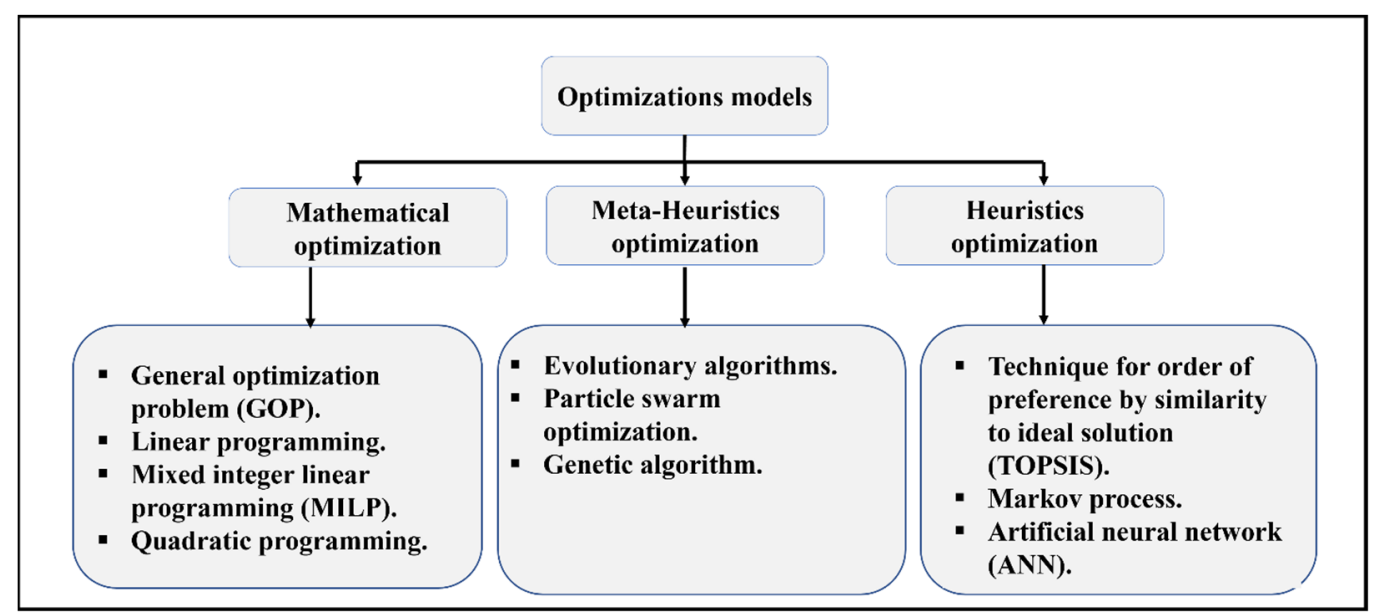

Figure 8. The schematic diagram for the main classification of optimization methods.

\subsection{Mathematical Models}

Integer programming, general optimization problem (GOP), and quadratic programming methods, defined as mathematical optimization methods, are typically used to achieve the optimal configuration of a BEB system to accurately calculate their energy consumption. Various studies have applied the integer programming method to optimize the BEB system configuration, which can be used to determine accurate modeling for the BEBs energy consumption.

For example, El-Taweel et al. [87] developed a mathematical optimization model based on a mixed-integer nonlinear programming problem (MINLP), which is solved using the basic open-source nonlinear mixed-integer programming optimization solver. They developed a mathematical formulation of the MINLP model based on an integrated utility-transit model incorporated with a highly accurate model of BEB energy consumption to optimize the BEB system configuration. In addition, they reported that BEB energy consumption is a crucial factor used to compute the optimal configuration of the BEB charger and its battery size, which can support the requirements of the transit schedule. Moreover, the minimal number and placement of required charging stations for a bus network, as well as the acceptable battery capacity for each bus route, were investigated using a mixed-integer linear optimization model, where the bus energy consumption for every part of the trip was computed according to bus type, individual route, and traffic conditions [88]. Previous studies have applied GOP to determine the optimal parameter design model in order to deploy an estimation energy consumption model for electric buses. For instance, Jang and Suh [89] developed the formulation of the GOP model to assess the energy consumption between a pair of bus stops instead of an electric transit bus system. They proposed an online electric vehicle using wireless power transfer technology to determine the optimal values of the battery size based on the charging infrastructure. Based on the analysis done in [90], it can be stated that, in terms of operating expenses, ICEV vehicles are unparalleled due to the current infrastructure and operating costs, as well as the frequency of failure of PHEV and BEV drives.

Mathematical optimizations methods are used extensively throughout the literature that focuses on optimizing the elements of the EB transport system to provide optimal outcomes with relatively minimal computational demand. As a result, mathematical optimizations methods can be applied to establish the charging schedules for electric buses; these deliver a trade-off between minimizing the power grid congestion and meeting the transportation network constraints.

\subsection{Meta-Heuristic Algorithms}

Over the last few decades, a wide range of studies has demonstrated the use of meta-heuristic algorithms, and these algorithms are becoming a significant measure of 
modern optimization. The genetic algorithm (GA) and PSO, which are defined as metaheuristic algorithms, are becoming increasingly popular [91,92]. Kennedy and Eberhart developed the PSO algorithm in 1995, this algorithm has been built based on swarm behavior in nature such as birds flocking and fish schooling behavior [88]. The simplicity of the PSO algorithm is considered one of the main advantages compared to other metaheuristic optimization algorithms. Besides, it requires minimal starting parameters and has a more intuitive searching function [93-95]. In [96], the PSO algorithm is developed as a technique for solving the optimization problem. The charging rate and BEB energy consumption rate were analytically modeled to optimally locate the transmitters and estimate battery capacity.

All surveyed published studies that were conducted with the meta-heuristic algorithms were targeted to design multiple optimum elements of the planned transport system, which include EB charging schedules, sizing the charging stations, and sizing the battery energy storage. These optimal elements can provide a sufficiently good solution to the optimization problem of EBs' energy consumption, particularly with limited computation capacity. For complex decision-making problems regarding the estimation of the energy consumption of EBs in transportation networks, heuristic algorithms generate near-optimal solutions or suboptimal solutions. For further studies on this topic, the optimization problem for the estimation of highly accurate values of BEB energy consumption based on a solution procedure with the PSO algorithm is shown in Figure 9.The solution procedure is described as follows:

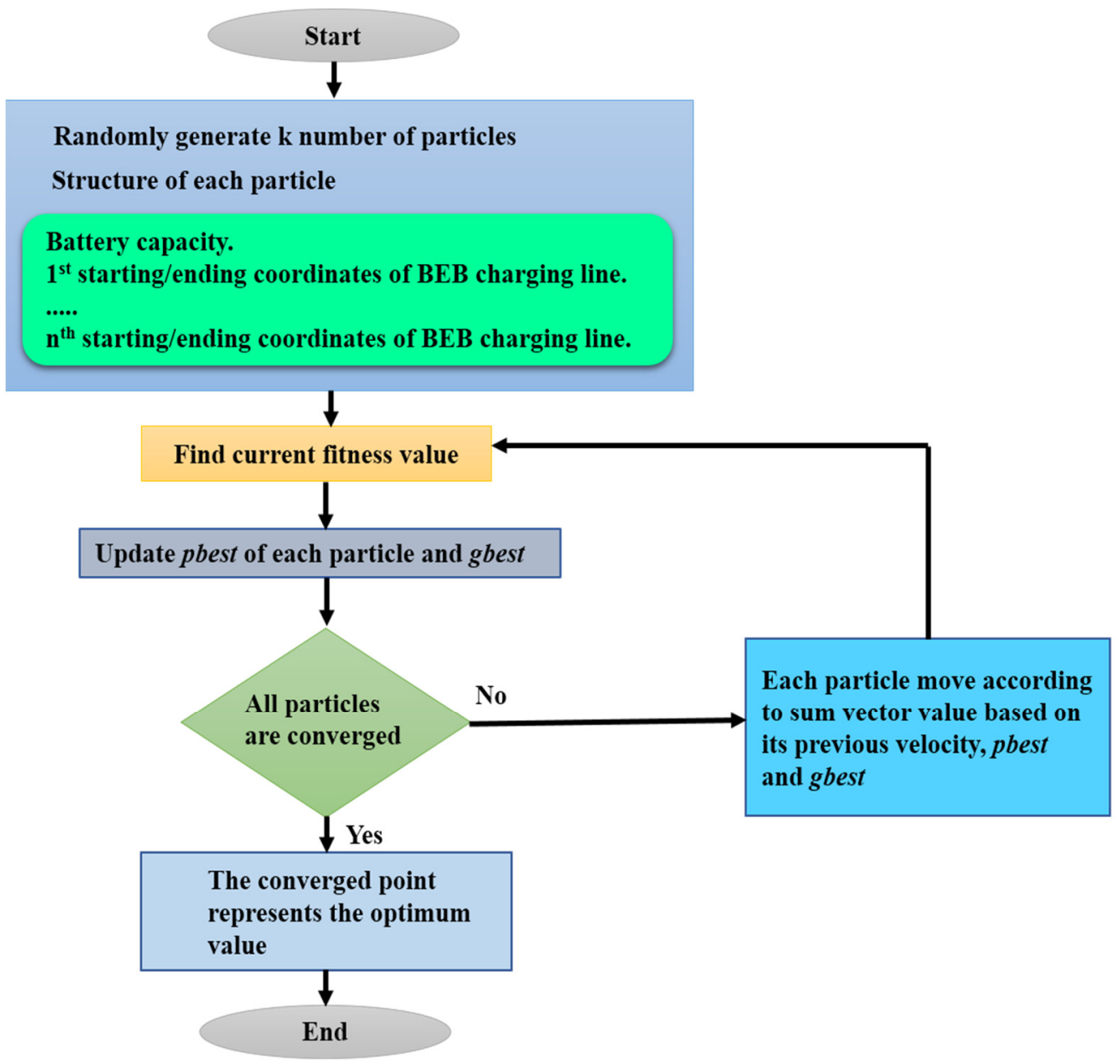

Figure 9. Solution procedure with PSO algorithm of the optimization problem for estimation of highly accurate values of BEB energy consumption. 
a. A number of particles $(k)$ : this stage randomly generates the candidate solutions of multiple particles within the feasible solution space associated with the position of a particle $\lambda_{s}(n)$. The outcome of this stage is the structure of each particle, which comprises multiple parameters of the BEBs system configuration.

b. Fitness value: the current objective function is evaluated in the optimization problem.

c. Comparing all particles: in the current iteration, the fitness value is to be compared with the prior best. In addition, the group best (gbest) and individual (pbest) is updated in this stage.

d. Velocity evaluation:the magnitude and direction of each particle, which is denoted by $v_{S}(n)$, can be evaluated in this stage. Then, the particles with the position and velocities are updated by applying the following equation:

$$
\lambda_{S}(n+1)=\lambda_{S}(n)+u_{S}(n+1)
$$

where $\alpha_{1}$ and $\alpha_{2}$ are the values of acceleration parameters, while the values of rand1 and rand2, which are referred to as uniform random numbers, are between 0 and 1 .

e. The procedure is repeated: to meet the termination criteria, stage (b) until stage (d) have to be repeated.

GA is inspired by natural evolution and Darwin's evolutionary theories such as mutation, crossover, inheritance, and selection. It is a search heuristic that creates solutions to optimization problems [97]. More detailed explanations about GA can be found in [98], where a driving plan optimization of regional electric buses considering the charging time window is modeled based on the GA optimization method, as shown in Figure 10. By using the GA algorithm, an optimized speed profile was generated concerning energy consumption via considering two different case studies, where the desired average speed was set either to $10 \mathrm{~km} / \mathrm{h}$ or $15 \mathrm{~km} / \mathrm{h}$ [99].

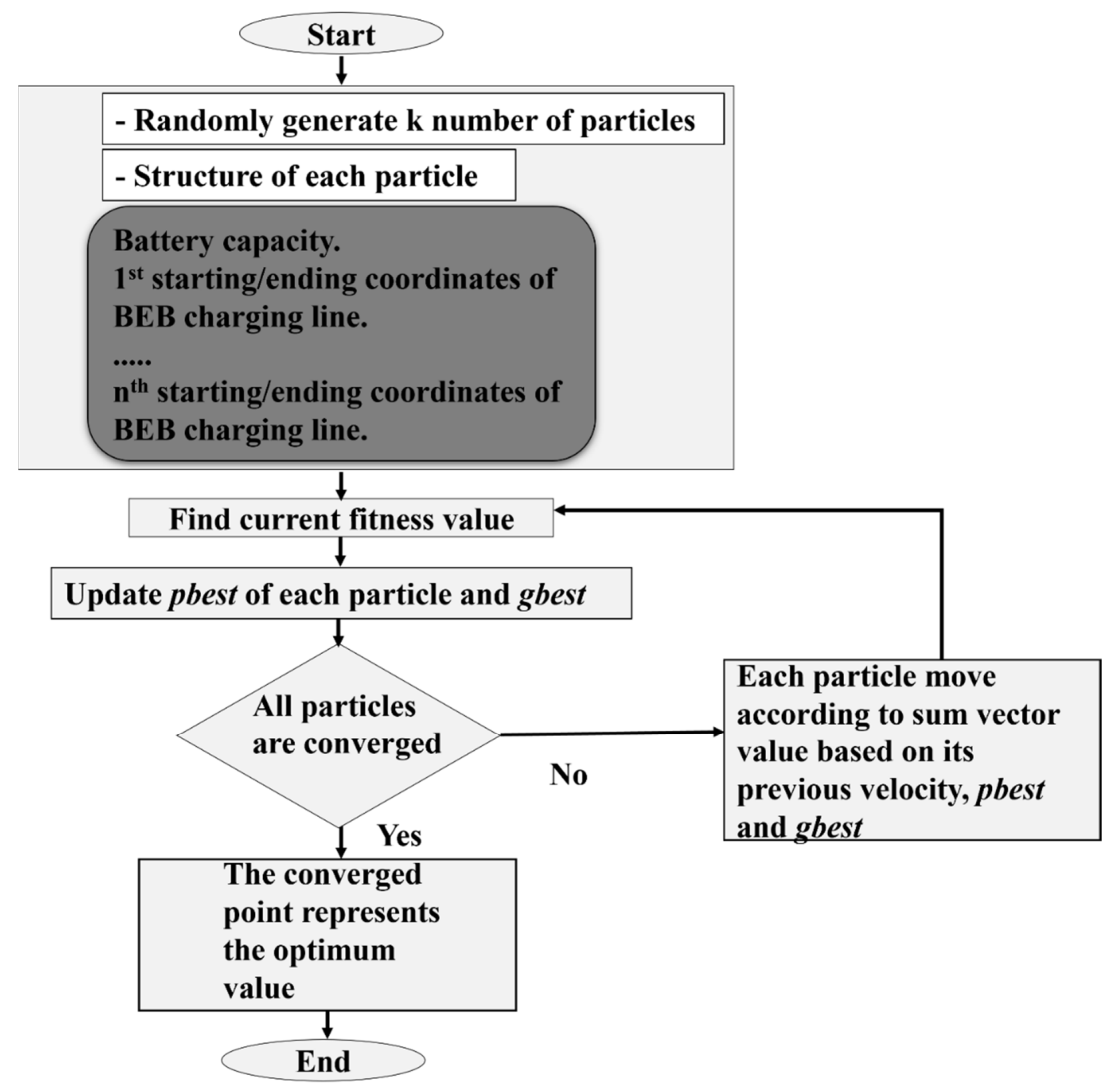

Figure 10. Genetic algorithm optimization method associated with driving plan optimization of regional electric buses. 


\subsection{Heuristic Optimization}

Heuristic optimization procedures are extremely fast in achieving optimal solutions to optimization problems for which computational approaches are incapable of providing optimum solutions in a finite time [100]. Backpropagation, an abbreviation for "backward propagation of errors", is a famous technique for training ANN applied in combination with an optimization approach such as gradient descent. In this context, an optimization approach employs the gradient to update the weights in an effort to reduce the loss function as much as possible [101]. The authors of this paper propose a generic framework to solve an optimization problem in the estimation of BEB energy consumption according to the ANN model, as shown in Figure 11. In the first stage of this framework, the dataset in the domain of the variables is generated to train a neural network. Then, a polynomial equation is formulated to resolve the optimization problem by redefining the objective function of the optimization problem with a multilayer perceptron [101]. There are three machinelearning approaches for estimating energy consumption: linear regression, artificial neural networks, and decision-tree models, which have been presented in [102]. As a result, all models were adjusted to minimize the mean squared error (MSE), which explains why ANN had a marginally lower performance in MAE tests.

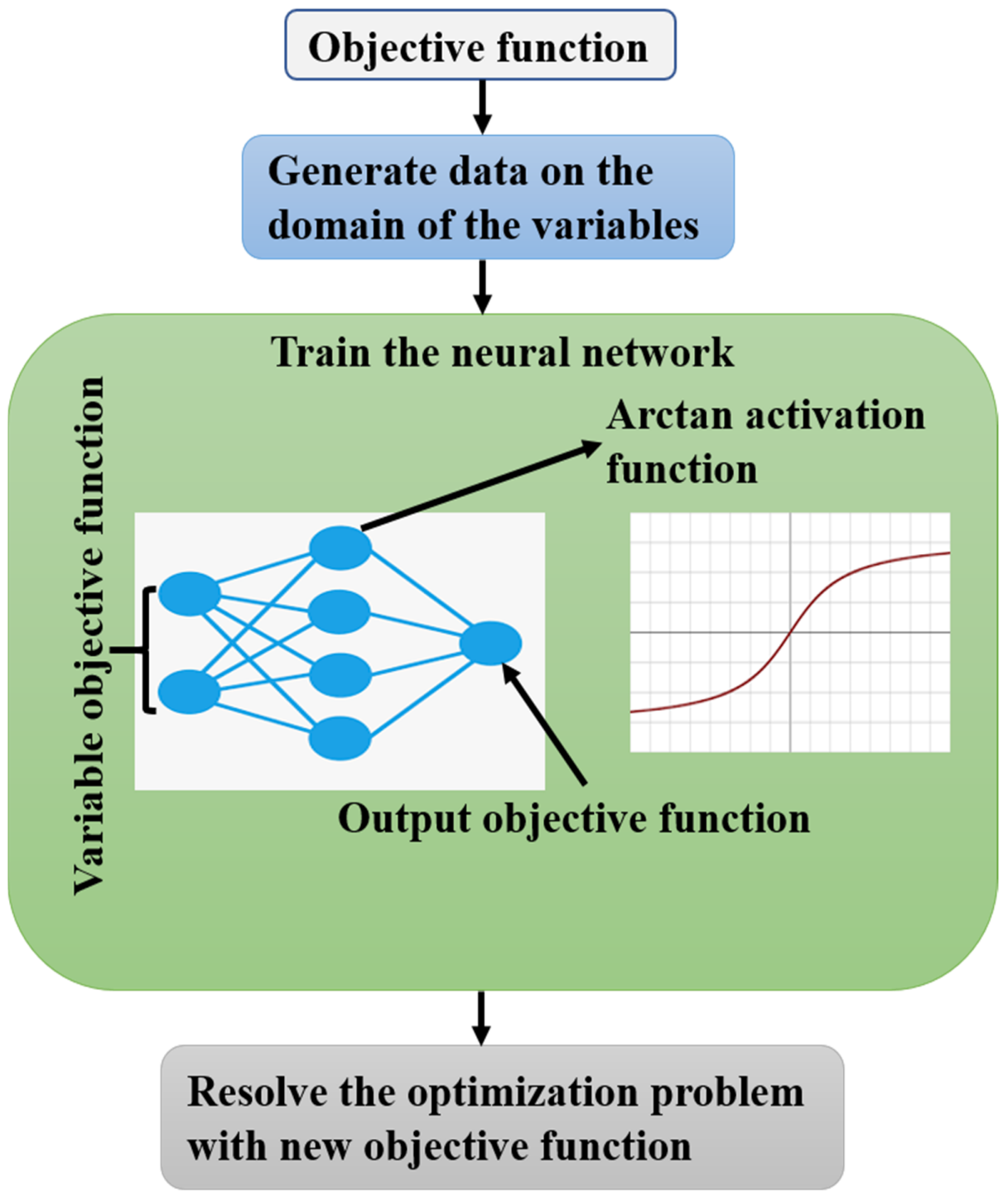

Figure 11. Generic framework to solve an optimization problem in estimations of BEB energy consumption based on ANN model. 


\section{Issues and Suggestions}

After investigating the techniques and methods and conducting a comprehensive review of many models for estimating the energy consumption of BEBs, some major issues and challenges were indicated and these are discussed in this section. Furthermore, possible solutions are also suggested in relation to each challenge.

\subsection{The Impact of External Factors}

Quantifying the impact of various external factors on BEB energy consumption is a necessity. The electrification of an urban public transport system with BEBs requires an accurate prediction of energy consumption because the estimated values of energy consumption significantly impact across three domains: energy management, economic, and environmental aspects [28,103]. In addition, energy consumption models that accurately and reliably estimate electricity use are critical to BEBs gaining wide acceptance. However, it is critical to understand how factors such as weather and legislation affect, for example, how much electricity people use. Haze has gotten worse in some locations over the last few years, which affects driving conditions and resident's travel habits. However, in current estimation approaches, these variables are rarely combined with energy use. As a result, it is difficult to create a model of the relationship between energy consumption and external elements after condition identification, as well as a lack of interest in the forecasting of future driving circumstances [104]. Understanding the effects of those factors is critical to achieving a highly accurate model for estimating the energy consumption of BEBs that can also contribute to the formulation of specialized, dynamic guidelines for energy consumption, particularly in relation to weather and policy situations. For the investigation of the impact of numerous external factors on energy usage on bus travels, Gao et al. [74] recommended the use of grey relational analysis (GRA). When evaluating energy consumption, variables including journey time, weather, distance traveled, and whether air conditioning were used and all have a significant impact.

\subsection{Replicate the Real-World Data}

Replicating real-world datasets for BEBs is another difficulty in estimating the real dynamic energy consumption; thus, it is another barrier that affects the adoption of BEBs. With many methods and techniques reviewed in this study, it was identified that estimation of energy consumption of BEBs mostly depends on various dynamic input parameters, such as traffic conditions and drivers' behavior. These dynamic parameters are difficult to replicate in modeling to match that of the real energy consumption values, especially with big-city depot bus networks. In addition, the models for estimating BEBs' energy consumption are imprecise for dynamic simulation applications. Thus, real-world energy consumption prediction is a difficult task that necessitates accurately reproducing the features of several subsystems in the real-world data employed in the BEB. To model an exact driving cycle, the German Aerospace Center's Institute of Transportation Systems created an open-source traffic simulation program that simply requires route and vehicle information [105]. It is a microscopic modelnamed the simulation of urban mobility(SUMO), whereby each vehicle is separately simulated.

\subsection{Big Data Analytics}

Big data's scope and challenges are frequently defined in terms of three characteristics: speed, volume, and variety [106]. To estimate BEB energy consumption and accurately anticipate consumption on any road in a road network, extensive datasets are needed that combine real-world observed driving data with geographic and weather data. Therefore, the resolution of big data analytics is required to indicate a highly efficient model that could be applied for estimating the BEB energy consumption of a bus network. Thus, the huge amount of this data coupled with data generated by the power grid constitutes the big data challenge [107]. Studies that have used deep learning networks (DLN), for example [7,108], have already provided promising results in the proper estimation of energy consumption 
with different-sized transport networks associated with large datasets. Furthermore, it is recommended to apply cloud computing technologies integrated into deep learning techniques, where cloud computing can provide the ideal solution to manage various data sources in a distributed, dynamic and faster manner.

\subsection{Validity Index}

A vast number of studies on the estimation of BEBs energy consumption are reviewed in this study. It was established that the majority of research employs a variety of estimation methodologies and approaches on a variety of different-sized transport networks and evaluates performance using a variety of different validity indices. Additionally, the studies provide little information due to the results' dependence on validity indices and model parameters, which makes a comparison of the results obtained by various estimation BEBs energy consumption studies very difficult. To alleviate the comparison problem, this study recommends using statistical techniques to analyze the variability of the validity indices with respect to the model variables.

\subsection{Bus Routes' Topography}

Quantitative research on the impact of road gradient on EB usage is rarely conducted. Many conventional studies ignore the impact of route gradients, resulting in high estimation errors due to the difficulties of measuring the road gradient directly and the constraints regarding the accuracy of observed energy consumption. There is a lack of knowledge of the full impact of road gradient on energy use in energy usage models. The application of Geographical Information System (GIS) tools is recommended as these can determine the slopes of each single bus route.

\subsection{Varying Energy Losses}

Many variables and factors are taken into account in the studies and algorithms discussed above to predict the BEB energy consumption of a specific location, but none of them considers the varied energy losses that occur between the grid connection and the electric bus battery. Failing to account for efficiency variations in a variety of operating conditions could result in higher electric losses, which would have a greater impact on the accuracy of the estimation of BEB energy consumption. Nevertheless, the authors in [32] presented a measurement method for loss calculation in electric vehicles in charging and discharging mode. The purpose of this model was to assess the round-trip energy losses from the grid entrance point to the energy storage battery. This was achieved through a series of experiments that put the system under charging and discharging cycles. It is recommended that this model be developed to be applicable in BEB studies associated with opportunity and overnight charging. Using real-world charging data to examine the charging flexibility potential of different electric vehicle fleets was introduced in [109]. The temporal and power-specific flexibility behavior of three separate vehicle fleets was explored in this research. These fleets were made up of office vehicles, vehicles from a public authority, and vehicles from a logistics company. In comparison to the office and public agency sites, the data analysis revealed that the logistics site had the most homogenous charging profile as well as the greatest charging flexibility.

\section{Conclusions and Discussions}

Knowledge of energy usage in the bus network is useful for planning bus fleet expansion, infrastructure modernization, and day-to-day operations management. A huge number of energy-deficient locations raise the question of whether it is more cost-effective to create charging stations or to purchase buses with larger batteries. This paper provides a summary of recent BEB energy consumption estimation research attempts. The impact of influential variables (vehicle components, driving dynamics, traffic, and environment), modeling scale (microscopic vs. macroscopic) and technique on energy consumption estimation models were examined (rule-based vs. data-driven). The qualities of the data 
employed in these models were also examined, as well as the data source (simulation vs. real world). However, the range estimators in the electric buses now on the market are insufficiently precise. More precise range estimate techniques are being studied as a solution to this problem. The electrification of buses in public transport systems with a focus on multiple approaches to estimate BEBs' energy consumption and the identified related issues are critically reviewed in this paper. The BEB is highly recommended by bus manufacturers because of its potential for reducing global warming and greenhouse gasses (GHG) emissions. This paper also provides a detailed review of the WTW assessment, which can be used to estimate the energy consumption of BEBs. The importance of WTB and BTW is explained by their ability to achieve a highly accurate assessment of BEB energy consumption. This review classifies the various approaches and methods into small-town depot and big-city depot networks. A detailed explanation, including model formulations, datasets collected, and error estimation from various algorithms are comprehensively reviewed. In order to accomplish optimal solutions to optimization problems, it is obvious from the studies that applied machine learning, particularly deep learning algorithms, that algorithms perform better than other mathematical models. In this regard, new deep learning algorithms are promising for further improvements in estimation performance, where these algorithms are highly accurate in modeling dynamic systems considering driver behaviors, weather, and traffic conditions. Considering the adaptability of the approaches investigated in this review, great enhancements can be achieved by adopting them for specific applications. For instance, the integrated machine learning and mathematical method provide a better estimation performance when compared to the use of a single method. Classification with an explanation of the methodologies of estimation BEB energy consumption will help bus manufacturers to obtain brief outlines and directions that could assist them to find a suitable estimation approach for their applications. This review highlighted multiple issues and challenges that are associated with obtaining estimates of BEB energy consumption, such as the impact of external factors, replicating real-world data, big data analytics, validity index, and bus routes' topography. The possible suggestions and adaptations also highlight each challenge. The details of different issues outlined in this paper could encourage researchers to conduct further research on how to mitigate these issues. The evaluated model might potentially be employed as a base for the calculation of electric bus ranges in future research. Additional information about the route, such as traffic and weather conditions, as well as the characteristics of the driver, should be included for this purpose. Furthermore, the battery model can be improved by taking into account the effects of battery state-of-charge (SoC) and state-of-health $(\mathrm{SoH})$, both of which have a significant impact on battery efficiency and energy consumption. The inertia of the vehicle's spinning components, such as the wheels, brakes, and rotor, can also be computed and included in the model to increase accuracy.

Author Contributions: Conceptualization: A.S.A.-O. and A.Q.A.-S.; Investigation: H.M.K.A.-M., T.S.B., Y.H., K.A., A.S.A.-O. and A.Q.A.-S.; Project Administration: T.S.B. and N.V.P.B.; Resources: A.S.A.-O., A.Q.A.-S., H.M.K.A.-M.; Supervision: A.S.A.-O.; A.Q.A.-S. and N.V.P.B.; Visualization: H.M.K.A.-M., T.S.B., Y.H., K.A. and A.S.A.-O.; Writing-Original Draft: A.S.A.-O. and A.Q.A.-S.; Writing-Review \& Editing: H.M.K.A.-M., T.S.B., Y.H., K.A. All authors have read and agreed to the published version of the manuscript.

Funding: Authors have received no external funding.

Institutional Review Board Statement: Not applicable.

Informed Consent Statement: Not applicable.

Data Availability Statement: Not applicable.

Conflicts of Interest: The authors declare that they have no known competing financial interest or personal relationship that could appear to influence the work reported in this paper. 


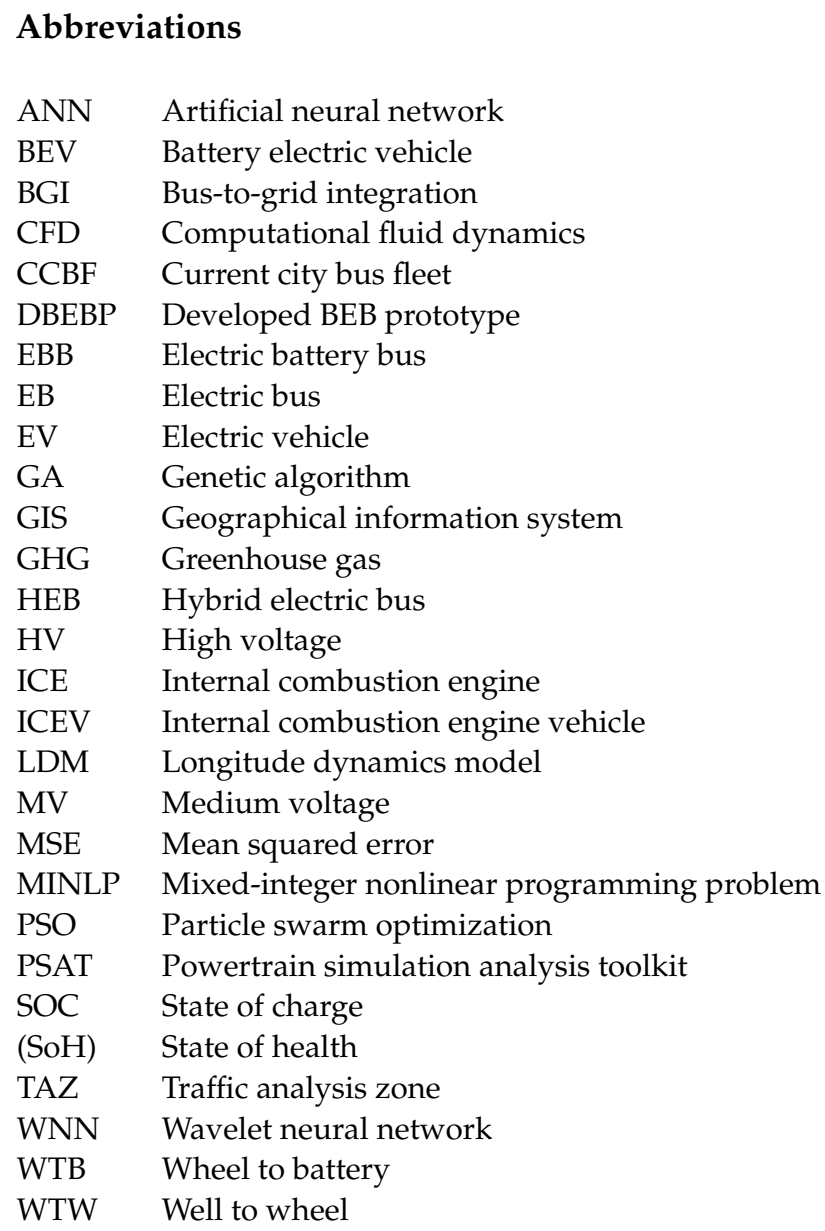

\section{References}

1. Wolinetz, M.; Wolinetz, M.; Axsen, J.; Peters, J.; Crawford, C. Simulating the value of electric-vehicle-grid integration using a behaviourally realistic model. Nat. Energy 2018, 3, 132-139. [CrossRef]

2. De Souza, L.L.P.; Lora, E.E.S.; Palacio, J.C.E.; Rocha, M.H.; Renó, M.L.G.; Venturini, O.J. Comparative environmental life cycle assessment of conventional vehicles with different fuel options, plug-in hybrid and electric vehicles for a sustainable transportation system in brazil. J. Clean. Prod. 2018, 203, 444-468. [CrossRef]

3. Muratori, M. Impact of uncoordinated plug-in electric vehicle charging on residential power demand. Nat. Energy 2018, 3, 193-201. [CrossRef]

4. Hariri, A.-M.; Hejazi, M.A.; Hashemi-Dezaki, H. Investigation of impacts of plug-in hybrid electric vehicles' stochastic characteristics modeling on smart grid reliability under different charging scenarios. J. Clean. Prod. 2021, 287, 125500. [CrossRef]

5. Brdulak, A.; Chaberek, G.; Jagodziński, J. Development forecasts for the zero-emission bus fleet in servicing public transport in chosen eu member countries. Energies 2020, 13, 4239. [CrossRef]

6. Song, Z.; Liu, Y.; Gao, H.; Li, S. The underlying reasons behind the development of public electric buses in china: The beijing case. Sustainability 2020, 12, 688. [CrossRef]

7. Pamuła, T.; Pamuła, W. Estimation of the energy consumption of battery electric buses for public transport networks using real-world data and deep learning. Energies 2020, 13, 2340. [CrossRef]

8. Mahmoud, M.; Garnett, R.; Ferguson, M.; Kanaroglou, P. Electric buses: A review of alternative powertrains. Renew. Sustain. Energy Rev. 2016, 62, 673-684. [CrossRef]

9. Yan, M.; He, H.; Li, M.; Li, G.; Zhang, X.; Chen, Z. A comprehensive life cycle assessment on dual-source pure electric bus. J. Clean. Prod. 2020, 276, 122702. [CrossRef]

10. Pelegov, D.V.; Pontes, J. Main drivers of battery industry changes: Electric vehicles-A market overview. Batteries 2018, 4, 65. [CrossRef]

11. Industry Report 2025. Electric Bus Market Size, Share, Trends: Global Electric Bus Market Overview. Available online: https:/ / www.psmarketresearch.com/market-analysis/electric-bus-market\#: \{\}:text=The\%20global\%20electric\%20bus\%20 market, 16.6\%25\%20during\%20the\%20forecast\%20period (accessed on 5 April 2021).

12. Sorrentino, M.; Rizzo, G.; Sorrentino, L. A study aimed at assessing the potential impact of vehicle electrification on grid infrastructure and road-traffic green house emissions. Appl. Energy 2014, 120, 31-40. [CrossRef] 
13. De Filippo, G.; Marano, V.; Sioshansi, R. Simulation of an electric transportation system at the ohio state university. Appl. Energy 2014, 113, 1686-1691. [CrossRef]

14. Poullikkas, A. Sustainable options for electric vehicle technologies. Renew. Sustain. Energy Rev. 2015, 41, 1277-1287. [CrossRef]

15. Zhou, B.; Wu, Y.; Zhou, B.; Wang, R.; Ke, W.; Zhang, S.; Hao, J. Real-world performance of battery electric buses and their life-cycle benefits with respect to energy consumption and carbon dioxide emissions. Energy 2016, 96, 603-613. [CrossRef]

16. Teoh, L.E.; Khoo, H.L.; Goh, S.Y.; Chong, L.M. Scenario-based electric bus operation: A case study of putrajaya, malaysia. Int. J. Transp. Sci. Technol. 2018, 7, 10-25. [CrossRef]

17. Vilppo, O.; Markkula, J. Feasibility of electric buses in public transport. World Electr. Veh. J. 2015, 7, 357-365. [CrossRef]

18. Gao, Z.; Lin, Z.; LaClair, T.J.; Liu, C.; Li, J.-M.; Birky, A.K.; Ward, J. Battery capacity and recharging needs for electric buses in city transit service. Energy 2017, 122, 588-600. [CrossRef]

19. He, X.; Zhang, S.; Ke, W.; Zheng, Y.; Zhou, B.; Liang, X.; Wu, Y. Energy consumption and well-to-wheels air pollutant emissions of battery electric buses under complex operating conditions and implications on fleet electrification. J. Clean. Prod. 2018, 171, 714-722. [CrossRef]

20. Suh, I.-S.; Lee, M.; Kim, J.; Oh, S.T.; Won, J.-P. Design and experimental analysis of an efficient hvac (heating, ventilation, air-conditioning) system on an electric bus with dynamic on-road wireless charging. Energy 2015, 81, 262-273. [CrossRef]

21. Lajunen, A. Energy consumption and cost-benefit analysis of hybrid and electric city buses. Transp. Res. Part C Emerg. Technol. 2014, 38, 1-15. [CrossRef]

22. Ou, X.; Zhang, X.; Chang, S. Alternative fuel buses currently in use in china: Life-cycle fossil energy use, ghg emissions and policy recommendations. Energy Policy 2010, 38, 406-418. [CrossRef]

23. Nylund, N.-O.; Koponen, K. Fuel and Technology Alternatives for Buses: Overall Energy Efficiency and Emission Performance; VTT Technical Research Centre of Finland: Helsinki, Finland, 2012.

24. Nurhadi, L.; Borén, S.; Ny, H. A sensitivity analysis of total cost of ownership for electric public bus transport systems in swedish medium sized cities. Transp. Res. Procedia 2014, 3, 818-827. [CrossRef]

25. Ribau, J.P.; Silva, C.M.; Sousa, J.M. Efficiency, cost and life cycle co2 optimization of fuel cell hybrid and plug-in hybrid urban buses. Appl. Energy 2014, 129, 320-335. [CrossRef]

26. McKenzie, E.C.; Durango-Cohen, P.L. Environmental life-cycle assessment of transit buses with alternative fuel technology. Transp. Res. Part D Transp. Environ. 2012, 17, 39-47. [CrossRef]

27. Torchio, M.F.; Santarelli, M.G. Energy, environmental and economic comparison of different powertrain/fuel options using well-to-wheels assessment, energy and external costs-european market analysis. Energy 2010, 35, 4156-4171. [CrossRef]

28. Vepsäläinen, J.; Otto, K.; Lajunen, A.; Tammi, K. Computationally efficient model for energy demand prediction of electric city bus in varying operating conditions. Energy 2019, 169, 433. [CrossRef]

29. Gallet, M.; Massier, T.; Hamacher, T. Estimation of the energy demand of electric buses based on real-world data for large-scale public transport networks. Appl. Energy 2018, 230, 344-356. [CrossRef]

30. Athanasopoulou, L.; Bikas, H.; Stavropoulos, P. Comparative well-to-wheel emissions assessment of internal combustion engine and battery electric vehicles. Procedia CIRP 2018, 78, 25-30. [CrossRef]

31. Doyle, D.; Harris, A.; Chege, S.; Douglas, L.; Early, J.; Best, R. Hydrogen Fuel Cell Buses: Modelling and Analysing Suitability from an Operational and Environmental Perspective; SAE International: Warrendale, PA, USA, 2020.

32. Pietrzak, O.; Pietrzak, K. The economic effects of electromobility in sustainable urban public transport. Energies 2021, 14, 878. [CrossRef]

33. Correa, G.; Muñoz, P.; Falaguerra, T.; Rodriguez, C. Performance comparison of conventional, hybrid, hydrogen and electric urban buses using well to wheel analysis. Energy 2017, 141, 537-549. [CrossRef]

34. Mao, F.; Li, Z.; Zhang, K. A comparison of carbon dioxide emissions between battery electric buses and conventional diesel buses. Sustainability 2021, 13, 5170. [CrossRef]

35. Kosai, S.; Nakanishi, M.; Yamasue, E. Vehicle energy efficiency evaluation from well-to-wheel lifecycle perspective. Transp. Res. Part D: Transp. Environ. 2018, 65, 355-367. [CrossRef]

36. Gustafsson, M.; Svensson, N.; Anderberg, S. Energy performance indicators as policy support for public bus transport-the case of sweden. Transp. Res. Part D: Transp. Environ. 2018, 65, 697-709. [CrossRef]

37. Petrides, D.; Papacharalampopoulos, A.; Stavropoulos, P.; Chryssolouris, G. Dematerialization and environmental sustainability: Challenges and rebound effects. Procedia CIRP 2018, 72, 845-849. [CrossRef]

38. Apostolaki-Iosifidou, E.; Codani, P.; Kempton, W. Measurement of power loss during electric vehicle charging and discharging. Energy 2017, 127, 730-742. [CrossRef]

39. Boribun, B.; Paolaor, P.; Kulworawanichpong, T. Impact of Electric Bus Charging in Power Distribution Systems. In Proceedings of the 2019 IEEE PES GTD Grand International Conference and Exposition Asia (GTD Asia), Bangkok, Thailand, 19-23 March 2019; pp. 25-28.

40. Jajczyk, J.; Dobrzycki, A.; Filipiak, M.; Kurz, D. Analysis of Power and Energy Losses in Power Systems of Electric Bus Battery Charging Stations; E3S Web of Conferences; EDP Sciences: Polanica Zdrój, Poland, 2017; p. 01027.

41. Campanari, S.; Manzolini, G.; De la Iglesia, F.G. Energy analysis of electric vehicles using batteries or fuel cells through well-to-wheel driving cycle simulations. J. Power Sources 2009, 186, 464-477. [CrossRef] 
42. Hannan, M.; Al-Shetwi, A.Q.; Begum, R.; Ker, P.J.; Rahman, S.; Mansor, M.; Mia, M.; Muttaqi, K.; Dong, Z. Impact assessment of battery energy storage systems towards achieving sustainable development goals. J. Energy Storage 2021, 42, 103040. [CrossRef]

43. Sánchez, J.A.G.; Martínez, J.M.L.; Martín, J.L.; Holgado, M.N.F.; Morales, H.A. Impact of spanish electricity mix, over the period 2008-2030, on the life cycle energy consumption and ghg emissions of electric, hybrid diesel-electric, fuel cell hybrid and diesel bus of the madrid transportation system. Energy Convers. Manag. 2013, 74, 332-343. [CrossRef]

44. Sulaiman, N.; Hannan, M.; Mohamed, A.; Majlan, E.; Daud, W.W. A review on energy management system for fuel cell hybrid electric vehicle: Issues and challenges. Renew. Sustain. Energy Rev. 2015, 52, 802-814. [CrossRef]

45. Al-Ogaili, A.S.; Al-Shetwi, A.Q.; Sudhakar Babu, T.; Hoon, Y.; Abdullah, M.A.; Alhasan, A.; Al-Sharaa, A. Electric buses in malaysia: Policies, innovations, technologies and life cycle evaluations. Sustainability 2021, 13, 11577. [CrossRef]

46. Alfalahi, S.T.; Alkahtani, A.A.; Al-Shetwi, A.Q.; Al-Ogaili, A.S.; Abbood, A.A.; Mansor, M.B.; Fazea, Y. Supraharmonics in power grid: Identification, standards, and measurement techniques. IEEE Access 2021, 9, 103677-103690. [CrossRef]

47. Yang, X.; Lu, S.; Zhao, W.; Zhao, Z. Exploring the characteristics of an intra-urban bus service network: A case study of shenzhen, china. ISPRS Int. J. Geo-Inf. 2019, 8, 486. [CrossRef]

48. Gabriel, N.R.; Martin, K.K.; Haslam, S.J.; Faile, J.C.; Kamens, R.M.; Gheewala, S.H. A comparative life cycle assessment of electric, compressed natural gas, and diesel buses in thailand. J. Clean. Prod. 2021, 314, 128013. [CrossRef]

49. Ding, R. The complex network theory-based urban land-use and transport interaction studies. Complexity 2019, $2019,4180890$. [CrossRef]

50. Bak, D.-B.; Bak, J.-S.; Kim, S.-Y. Strategies for implementing public service electric bus lines by charging type in daegu metropolitan city, south korea. Sustainability 2018, 10, 3386. [CrossRef]

51. Hinse, P.R. Energy Use Analysis and Technology for Electric Transit Buses; UOIT: Zug, Switzerland, 2010.

52. Pavlyuk, D. Feature selection and extraction in spatiotemporal traffic forecasting: A systematic literature review. Eur. Transp. Res. Rev. 2019, 11, 6. [CrossRef]

53. Paul, T.; Yamada, H. Operation and Charging Scheduling of Electric Buses in a City Bus Route Network. In Proceedings of the 17th International IEEE Conference on Intelligent Transportation Systems (ITSC), Qingdao, China, 8-11 October 2014; pp. $2780-2786$

54. Ke, B.-R.; Chung, C.-Y.; Chen, Y.-C. Minimizing the costs of constructing an all plug-in electric bus transportation system: A case study in penghu. Appl. Energy 2016, 177, 649-660. [CrossRef]

55. Xylia, M. Towards Electrified Public Bus Transport: The Case of Stockholm; KTH Royal Institute of Technology: Stockholm, Sweden, 2018.

56. Yan, Y.; Jiang, J.; Zhang, W.; Huang, M.; Chen, Q.; Wang, H. Research on power demand suppression based on charging optimization and bess configuration for fast-charging stations in beijing. Appl. Sci. 2018, 8, 1212. [CrossRef]

57. Liu, Y.; Yao, E.; Liu, S. Energy consumption optimization model of multi-type bus operating organization based on time-space network. Appl. Sci. 2019, 9, 3352. [CrossRef]

58. Fiori, C.; Ahn, K.; Rakha, H.A. Power-based electric vehicle energy consumption model: Model development and validation. Appl. Energy 2016, 168, 257-268. [CrossRef]

59. Rios, J.; Sauras-Perez, P.; Gil, A.; Lorico, A.; Taiber, J.; Pisu, P. Battery Electric Bus Simulator-A Tool for Energy Consumption Analysis; SAE International: Warrendale, PA, USA, 2020.

60. Rogge, M.; van der Hurk, E.; Larsen, A.; Sauer, D.U. Electric bus fleet size and mix problem with optimization of charging infrastructure. Appl. Energy 2018, 211, 282-295. [CrossRef]

61. Ly, T.; Goehlich, D.; Heide, L. Assessment of the Interaction of Charging System and Battery Technology for the Use in Urban Battery Electric Bus Systems. In Proceedings of the 2016 IEEE Vehicle Power and Propulsion Conference (VPPC), Hangzhou, China, 17-20 October 2016; pp. 1-6.

62. Hannan, M.; Al-Shetwi, A.Q.; Begum, R.; Young, S.; Hoque, M.; Ker, P.J.; Mansur, M.; Alzaareer, K. The value of thermal management control strategies for battery energy storage in grid decarbonization: Issues and recommendations. J. Clean. Prod. 2020, 276, 124223. [CrossRef]

63. Vepsäläinen, J.; Ritari, A.; Lajunen, A.; Kivekäs, K.; Tammi, K. Energy uncertainty analysis of electric buses. Energies 2018, 11, 3267. [CrossRef]

64. Łebkowski, A. Studies of energy consumption by a city bus powered by a hybrid energy storage system in variable road conditions. Energies 2019, 12, 951. [CrossRef]

65. Erkkilä, K.; Nylund, N.-O.; Pellikka, A.-P.; Kallio, M.; Kallonen, S.; Ojamo, S.; Ruotsalainen, S.; Pietikäinen, O.; Lajunen, A. Ebus-electric Bus Test Platform in Finland. In Proceedings of the 27th International Electric Vehicle Symposium \& Exhibition (EVS27), Barcelona, Spain, 17-20 November 2013.

66. Feng, C.; Zheng, C.-J.; Shan, M.-L. The clarification for the features, temporal variations, and potential factors of global carbon dioxide emissions. J. Clean. Prod. 2020, 255, 120250. [CrossRef]

67. Miller, S.A.; John, V.M.; Pacca, S.A.; Horvath, A. Carbon dioxide reduction potential in the global cement industry by 2050. Cem. Concr. Res. 2018, 114, 115-124. [CrossRef]

68. Li, Y.; Huang, X.; Liu, D.; Wang, M.; Xu, J. Hybrid energy storage system and energy distribution strategy for four-wheel independent-drive electric vehicles. J. Clean. Prod. 2019, 220, 756-770. [CrossRef] 
69. EPA. Vehicle and Fuel Emissions Ttesting-Dynamometer Drive Schedules. Available online: https:/ /www.epa.gov/vehicle-andfuel-emissions-testing/dynamometer-drive-schedules (accessed on 12 May 2021).

70. DieselNet. Emission Test Cycles. Available online: https://www.dieselnet.com/standards/cycles/index (accessed on 2 May 2021).

71. Fontaras, G.; Zacharof, N.-G.; Ciuffo, B. Fuel consumption and $\mathrm{CO}_{2}$ emissions from passenger cars in europe-laboratory versus real-world emissions. Prog. Energy Combust. Sci. 2017, 60, 97-131. [CrossRef]

72. UNECE. World Forum for Harmonization of Vehicle Regulations. Available online: http://www.unece.org/trans/main/wp29/ meeting_docs_wp29.html (accessed on 12 May 2021).

73. Nylund, N.-O.; Erkkilä, K.; Clark, N.; Rideout, G. Evaluation of Duty Cycles for Heavy-Duty Urban Vehicles: Final Report of Iea Amf Annex Xxix. 2007. Available online: http:/ /www.vtt.fi/inf/pdf/tiedotteet/2007/T2396.pdf (accessed on 23 May 2021).

74. Gis, W.; Kruczyński, S.; Taubert, S.; Wierzejski, A. Studies of energy use by electric buses in sort tests. Combust. Engines 2017, 56, 135-138. [CrossRef]

75. Lajunen, A.; Lipman, T. Lifecycle cost assessment and carbon dioxide emissions of diesel, natural gas, hybrid electric, fuel cell hybrid and electric transit buses. Energy 2016, 106, 329-342. [CrossRef]

76. Shadab Mehr, H.; Rahnama, M.R.; Shokouhi, M.A.; Mafi, E. Optimization of main public transport paths based on accessibilitycase study: Mashhad, iran. J. Public Transp. 2016, 19, 8. [CrossRef]

77. Sinhuber, P.; Rohlfs, W.; Sauer, D.U. Study on Power and Energy Demand for Sizing the Energy Storage Systems for Electrified Local Public Transport Buses. In Proceedings of the 2012 IEEE Vehicle Power and Propulsion Conference, Seoul, Korea, 9-12 October 2012; pp. 315-320.

78. Abdella, G.M.; Kucukvar, M.; Onat, N.C.; Al-Yafay, H.M.; Bulak, M.E. Sustainability assessment and modeling based on supervised machine learning techniques: The case for food consumption. J. Clean. Prod. 2020, 251, 119661. [CrossRef]

79. She, C.; Wang, Z.; Sun, F.; Liu, P.; Zhang, L. Battery aging assessment for real-world electric buses based on incremental capacity analysis and radial basis function neural network. IEEE Trans. Ind. Inform. 2019, 16, 3345-3354. [CrossRef]

80. Gao, Y.; Guo, S.; Ren, J.; Zhao, Z.; Ehsan, A.; Zheng, Y. An electric bus power consumption model and optimization of charging scheduling concerning multi-external factors. Energies 2018, 11, 2060. [CrossRef]

81. Zhao, X.; Ma, J.; Liu, R.; Wang, G. Multiple parameters state-of-charge estimation of battery for pure electric bus based on ggap-rbf neural network. China J. Highw. Transp. 2015, 28, 116-126.

82. Nageshrao, S.P.; Jacob, J.; Wilkins, S. Charging cost optimization for ev buses using neural network based energy predictor. IFAC-Pap. 2017, 50, 5947-5952. [CrossRef]

83. Schwertner, N.; Macht, G. Energy Consumption Estimation for Routing Evs Based on Driver Behavior. In Proceedings of the 2018 IISE Annual Conference, Kingston, RI, USA, 21-24 May 2018.

84. De Cauwer, C.; Verbeke, W.; Coosemans, T.; Faid, S.; Van Mierlo, J. A data-driven method for energy consumption prediction and energy-efficient routing of electric vehicles in real-world conditions. Energies 2017, 10, 608. [CrossRef]

85. Gonçalves, P.C.; Monteiro, L.P.C.; de Sousa Santos, L. Multi-objective optimization of a biodiesel production process using process simulation. J. Clean. Prod. 2020, 270, 122322. [CrossRef]

86. Yildiz, B.; Bilbao, J.I.; Dore, J.; Sproul, A.B. Recent advances in the analysis of residential electricity consumption and applications of smart meter data. Appl. Energy 2017, 208, 402-427. [CrossRef]

87. El-Taweel, N.A.; Farag, H.E.; Mohamed, M. Integrated utility-transit model for optimal configuration of battery electric bus systems. IEEE Syst. J. 2019, 14, 738-748. [CrossRef]

88. Kunith, A.; Mendelevitch, R.; Goehlich, D. Electrification of a city bus network-An optimization model for cost-effective placing of charging infrastructure and battery sizing of fast-charging electric bus systems. Int. J. Sustain. Transp. 2017, 11, 707-720. [CrossRef]

89. Jang, Y.J.; Suh, E.S.; Kim, J.W. System architecture and mathematical models of electric transit bus system utilizing wireless power transfer technology. IEEE Syst. J. 2015, 10, 495-506. [CrossRef]

90. Wróblewski, P.; Drożdż, W.; Lewicki, W.; Miązek, P. Methodology for assessing the impact of aperiodic phenomena on the energy balance of propulsion engines in vehicle electromobility systems for given areas. Energies 2021, 14, 2314. [CrossRef]

91. Qian, X.; Jia, S.; Huang, K.; Chen, H.; Yuan, Y.; Zhang, L. Optimal design of kaibel dividing wall columns based on improved particle swarm optimization methods. J. Clean. Prod. 2020, 273, 123041. [CrossRef]

92. Shin, Y.; Kim, Z.; Yu, J.; Kim, G.; Hwang, S. Development of nox reduction system utilizing artificial neural network (ann) and genetic algorithm (ga). J. Clean. Prod. 2019, 232, 1418-1429. [CrossRef]

93. Abdolrasol, M.G.; Mohamed, R.; Hannan, M.; Al-Shetwi, A.Q.; Mansor, M.; Blaabjerg, F. Artificial neural network based particle swarm optimization for microgrid optimal energy scheduling. IEEE Trans. Power Electron. 2021, 36, 12151-12157. [CrossRef]

94. Parvin, K.; Hannan, M.; Al-Shetwi, A.Q.; Ker, P.J.; Roslan, M.; Mahlia, T.I. Fuzzy based particle swarm optimization for modeling home appliances towards energy saving and cost reduction under demand response consideration. IEEE Access 2020, 8 , 210784-210799. [CrossRef]

95. Hannan, M.; Tan, S.Y.; Al-Shetwi, A.Q.; Jern, K.P.; Begum, R. Optimised controller for renewable energy sources integration into microgrid: Functions, constraints and suggestions. J. Clean. Prod. 2020, 256, 120419. [CrossRef]

96. Ko, Y.D.; Jang, Y.J. The optimal system design of the online electric vehicle utilizing wireless power transmission technology. IEEE Trans. Intell. Transp. Syst. 2013, 14, 1255-1265. [CrossRef] 
97. Paulo, P.; Branco, F.; de Brito, J.; Silva, A. Buildingslife-the use of genetic algorithms for maintenance plan optimization. J. Clean. Prod. 2016, 121, 84-98. [CrossRef]

98. Liu, Y.; Yao, E.; Lu, M.; Yuan, L. Regional electric bus driving plan optimization algorithm considering charging time window. Math. Probl. Eng. 2019, 2019, 7863290. [CrossRef]

99. Torabi, S.; Bellone, M.; Wahde, M. Energy minimization for an electric bus using a genetic algorithm. Eur. Transp. Res. Rev. 2020, 12, 2. [CrossRef]

100. Demeler, B.; Zhou, G. Neural network optimization for e. Coli promoter prediction. Nucleic Acids Res. 1991, 19, 1593-1599. [CrossRef] [PubMed]

101. Villarrubia, G.; De Paz, J.F.; Chamoso, P.; De la Prieta, F. Artificial neural networks used in optimization problems. Neurocomputing 2018, 272, 10-16. [CrossRef]

102. Ayman, A.; Wilbur, M.; Sivagnanam, A.; Pugliese, P.; Dubey, A.; Laszka, A. Data-Driven Prediction of Route-Level Energy Use for Mixed-Vehicle Transit Fleets. In Proceedings of the 2020 IEEE International Conference on Smart Computing (SMARTCOMP), Bologna, Italy, 14-17 September 2020; pp. 41-48.

103. Li, N.; Zhang, J.; Zhang, S.; Hou, X.; Liu, Y. The influence of accessory energy consumption on evaluation method of braking energy recovery contribution rate. Energy Convers. Manag. 2018, 166, 545-555. [CrossRef]

104. Conti, V.; Orchi, S.; Valentini, M.P.; Nigro, M.; Calò, R. Design and evaluation of electric solutions for public transport. Transp. Res. Procedia 2017, 27, 117-124. [CrossRef]

105. Krajzewicz, D.; Erdmann, J.; Behrisch, M.; Bieker, L. Recent development and applications of sumo-simulation of urban mobility. Int. J. Adv. Syst. Meas. 2012, 5, 128-138.

106. Hadi, H.J.; Shnain, A.H.; Hadishaheed, S.; Ahmad, A.H. Big data and five v's characteristics. Int. J. Adv. Electron. Comput. Sci. 2015, 2, 16-23.

107. Li, B.; Kisacikoglu, M.C.; Liu, C.; Singh, N.; Erol-Kantarci, M. Big data analytics for electric vehicle integration in green smart cities. IEEE Commun. Mag. 2017, 55, 19-25. [CrossRef]

108. Cavanillas, J.M.; Curry, E.; Wahlster, W. New Horizons for a Data-Driven Economy: A Roadmap for Usage and Exploitation of Big Data in Europe; Springer Nature: New York, NY, USA, 2016; pp. 10-25. ISBN 978-3-319-79353-5.

109. Barthel, V.; Schlund, J.; Landes, P.; Brandmeier, V.; Pruckner, M. Analyzing the charging flexibility potential of different electric vehicle fleets using real-world charging data. Energies 2021, 14, 4961. [CrossRef] 